\title{
Notas sobre algunos principios generales del derecho: una reflexión a partir de principios generales y su influencia en las obligaciones en la experiencia jurídica colombiana Notes about Some General Principles of Law: A View of Some General Principles and Their Influence on The Law of Obligations in Colombian Legal Experience
}

\section{JOSÉ FÉLIX CHAMIE* \\ Universidad Externado de Colombia}

Resumen: En esta contribución se pretende abordar de manera sintética la influencia de algunos principios generales del derecho tomando como ejemplo las obligaciones a partir de la experiencia jurídica colombiana. Este escrito pretende contribuir a la sistematización, contenido y afirmación de los principios generales del derecho y, con ello, al avance de la ciencia jurídica y al progreso de la sociedad. El trabajo parte del derecho colombiano, pero se proyecta en perspectiva dentro de la tradición del sistema jurídico romanístico.

Palabras clave: principios generales del derecho, armonización del derecho, derecho de obligaciones, derecho privado, derecho civil y constitucional colombianos

\begin{abstract}
This paper is intended to address in a synthetic way but with recent citations of the doctrine and jurisprudence some general principles of law, in order to contribute to the systematization, content, and affirmation of the general principles of law, and so, achieve the goal of a better law, the development of legal science and the progress of society. This paper makes particular emphasis on Colombian law, but it is projected as well inside the civil law tradition.
\end{abstract}

Key words: principles of law, law of obligations, Colombian civil law, harmonization of law, private law

CONTENIDO: I. INTRODUCCIÓN.- II. PRINCIPIO DE LIBERTAD.- III. PRINCIPIO DE DIGNIDAD HUMANA.- IV. PRINCIPIO DE IGUALDAD.- V. PRINCIPIO DE SOLIDARIDAD.- VI. PRINCIPIO DE AUTONOMIIA PRIVADA.- VII. PRINCIPIO DE BUENA FE.- VIII. PRINCIPIO DE EQUIDAD.- IX. PRINCIPIO DE PROPORCIONALIDAD.- X. CONCLUSIONES.

* Profesor de derecho civil y derecho romano en la Universidad Externado de Colombia. Doctor en Derecho por la Universidad de Roma «Tor Vergata».

Código ORCID: 0000-0003-0246-0222. Correo electrónico: jose.chamie@uexternado.edu.co 


\section{INTRODUCCIÓN}

La tarea del jurista es fundamental no solo en el momento de la formación de las leyes, o en el momento de su interpretación y aplicación, sino también en el diálogo entre ordenamientos y sistemas, el diálogo para mejorar y armonizar el derecho, para identificar los principios generales, sistematizarlos, darles contorno, sentido, eficacia, arraigo social. Para cumplir esta función, el jurista emplea los principios generales del derecho como instrumento de avance, como un horizonte, pero a la vez como un desafío, para mejorar la ciencia del derecho, con esperanza y optimismo en mejorar la especie, y para el logro de la igualdad social (Hinestrosa, 1997, p. 7; véase Cortés, 2006, p. 570 y passim). A los tradicionales principios generales del derecho se suman unos aparentemente nuevos, de factura constitucional y que han venido influyendo en los principios de origen civilista, «constitucionalizándolos». Resulta conveniente enunciar algunos de estos principios y su relación, por ejemplo, con la materia de las obligaciones contractuales y, en lo posible, también respecto de las obligaciones extracontractuales o derivadas del daño. Desde ya se anticipa que no es la pretensión aquí realizar un catálogo exhaustivo de los principios generales en todo su alcance y operatividad, o de los principios generales del derecho - ello sería una meta inalcanzable-, tan solo se pretende enunciar algunos de ellos y la influencia del constitucionalismo en su apreciación o, incluso, preguntarse si principios constitucionales como dignidad humana y solidaridad puedan ser de recibo en la materia de las obligaciones. También se aclara que no se pretende confundir el solidarismo contractual con el principio constitucional de solidaridad, lo que en relación con esto se pretende es precisamente revisar si tal principio constitucional sea o no de aplicación en las obligaciones, independientemente del llamado solidarismo contractual y sin confundirlos. Asimismo, conviene aclarar desde ahora que cuando en este escrito se haga referencia a obligaciones derivadas del daño (responsabilidad extracontractual), no se trata de un error en el enfoque, sino de la pretensión de someter a prueba la institución jurídica unitaria de la «obligación» y, visto que una de sus fuentes es precisamente el daño, constatar si los principios generales de las obligaciones puedan o no ser de recibo en obligaciones de contrato y en obligaciones derivadas del daño, o si cada principio asuma una especificidad tal que no permita su aplicación en todo tipo de obligaciones. Por ejemplo, nadie pensaría que la autonomía privada tenga que ver con el derecho de daños. Pero tampoco podemos negar que, de otro lado, el principio de equidad informa tanto las obligaciones contractuales como la obligación de indemnizar el daño extracontractual en la medida en que en esta última la equidad se erige en límite a la fijación del monto de la obligación de indemnizar, y en las primeras interviene en varios instrumentos para el reajuste del turbado equilibrio en el contrato. 
Así pues, queda delimitado que el objeto del presente escrito no es realizar un tratamiento extenso de cada principio al que se haga referencia — se insiste, esa sería una pretensión demasiado ambiciosa-, lo que se pretende es reflexionar a partir de la influencia del constitucionalismo en la doctrina y la jurisprudencia colombianas en materia de principios de las obligaciones. Con este objeto, se han seleccionado algunos principios generales, unos de factura tradicional (buena fe, equidad) y otros con mayor reconocimiento desde la perspectiva constitucional (igualdad, dignidad humana, solidaridad).

No se pretende hacer una lista exhaustiva de los posibles principios en la actualidad; es apenas obvio que ello estaría fuera de alcance y sería una pretensión demasiado ambiciosa, en muchos volúmenes. Tampoco es la intención profundizar en las modalidades de aplicación. Además, el escrito parte en su análisis del ordenamiento y la doctrina colombianos, aunque en algunas ocasiones con cita de extranjera. Lo que se pretende es evidenciar que a los principios, por así decirlo, «tradicionales» se suman otros de reciente factura o, al menos, de reciente «relectura»o reciente «descubrimiento» (véase Metzger, 2009, pp. 7ss.) que deben ser acrecentados y sistematizados para esta materia. Apenas señalo aquí unos lineamientos.

Se insiste en la tarea del jurista en nuestro tiempo, especialmente el jurista del sistema romanista, llamado a contribuir en la profundización del diálogo entre los países del sistema, en nuestro caso los países latinoamericanos. Nuestro modelo de jurista, latinoamericano formado en Europa y dedicado tanto a la academia como a la práctica profesional, es un modelo integral de jurista del sistema por su autenticidad, su mezcla, su perspectiva, su herencia jurídica y su rol en el proceso de armonización del derecho en el continente. Resulta sugestiva una perspectiva romanística histórico-dogmática que encuentra seria justificación en el interior del sistema jurídico romanista también en su fase actual, cuando asistimos a un periodo de excesiva y dispersa legislación que reclama armonizar el derecho y conducirlo hacia una nueva fijación mediante los principios generales —un ius enucleatum, aquí «enucleado» en el sentido del adjetivo latino «claridad», «precisión», a las que se llega mediante una profunda reflexión (enucleata), necesaria para la búsqueda de los principios (véase Cicerón, De oratore, 91, Pro Scauro, 20, Pro Plancio, 10). Hay que hacerlo casi recordando la sentencia de Teodosio: «solum ius relinquatur, quod ut brevitate constrictum claritate luceat» (Codex Theodosianus, 1, 1, 6pr.-1), pero recordando también la empresa de Justiniano y sus motivaciones.

En relación con esto, tal y como afirma Schipani (2010, pp. 324ss.), se habla del «tradicionalismo del jurista», y esto significa la necesidad para el jurista contemporáneo de una educación histórica, la necesidad de

NOTAS SOBRE

ALGUNOS

PRINCIPIOS

GENERALES

DEL DERECHO:

UNA REFLEXIÓN

A PARTIR DE

PRINCIPIOS

GENERALES Y

SU INFLUENCIA

EN LAS

OBLIGACIONESEN

LA EXPERIENCIA

JURÍDICA

COLOMBIANA

NOTES ABOUT

SOME GENERAL

PRINCIPLES OF

LAW: A VIEW OF

SOME GENERAL

PRINCIPLES AND

THEIR INFLUENCE

ON THE LAW OF

OBLIGATIONS

IN COLOMBIAN

LEGAL

EXPERIENCE 
alimentarse, en su formación en derecho y en su «estilo mental», de la tradición-experiencia. Schipani recuerda que los esquemas jurídicos son esquemas de experiencia, y esta es un elemento racional de la tradición que se explica dentro de un contexto más amplio de búsqueda de verdades-valores, de principios (véase Grosso, 1976, passim; Schipani, 2010, pp. 324ss. y passim). De ahí que, cuando se habla de principios generales del derecho, sea inevitable que el intérprete se confronte, en su búsqueda, con toda la tradición del sistema incluso desde los tiempos de su formación (considérese en la fase actual del sistema la perspectiva de la armonización del derecho de principios de los contratos en Momberg, 2018; Momberg \& Vogenauer, 2017; tómese en cuenta también el trabajo del Grupo para la Armonización del Derecho en América Latina (GADAL) por un Código Marco de Obligaciones para América Latina).

Por otra parte, el discurso sobre las fuentes del derecho se torna relativo y discutible respecto del modelo tradicional de producción de derecho en el estatal-legalismo. La ley sigue siendo la fuente principal, pero una excesiva legislación hace que el sistema se sienta pesado, lento, ineficiente, a veces síntoma de caos y de impunidad. No obstante, el poder ejecutivo ha ido ganando prerrogativas y ha ido «expropiando» la ley, en la medida de su poder reglamentario, pero también por su iniciativa legislativa casi prevalente, indica que el poder de elaboración de las normas se ha trasladado al ejecutivo. Es decir, en cierto sentido, se trata de la pérdida de control del proceso legislativo en manos del ejecutivo (Chevallier, 2011, pp. 322 y passim). En todo caso, el jurista va más o menos marginado del proceso y se convierte en intérprete de lo hecho y en «operador jurídico». Por ello, es tan importante la dimensión de la tarea del jurista en los procesos de fijación y consolidación del derecho del sistema mediante la armonización (véase Schipani, 2010, passim).

Se identificará la influencia en general de los principios y, en particular, donde se pueda, la influencia de los principios tradicionales que rigen la disciplina de las obligaciones contractuales. En este caso, se habla en general de autonomía privada, libertad contractual, buena fe y equidad, responsabilidad prevalentemente patrimonial (para la armonización del derecho latinoamericano, véase Momberg, 2018; Momberg \& Vogenauer, 2017; Ferrante, 2016); y en las obligaciones derivadas del daño, se habla de reparación integral y también de equidad. Pero lo cierto es que las exigencias de nuestro tiempo y las características de nuestras sociedades hacen que a la lista tradicional de principios se sumen otros nuevos, de los que se dice que provienen del derecho constitucional o se destaca su marcada influencia en las instituciones del derecho privado debido a la supremacía de la Constitución (Constitución Política de Colombia, artículo 4). Considérense, en este sentido, las palabras de Hinestrosa: 
Aparte de la importancia sempiterna de los principios generales, que yacen vivos en los códigos, se anota que en el presente son numerosos e importantes los ejemplos de nuevos códigos y de reformas amplias y profundas de códigos tradicionales, lo cual mueve a pensar en que los códigos de por sí tienen aún una función que cumplir en cuanto a la disciplina de instituciones y figuras, y que su vigencia paralela a los estatutos especializados tiene un significado propio. [...] las instituciones que alcanzaron su apogeo en los dos últimos siglos: el derecho subjetivo, la propiedad, el contrato, la responsabilidad, que han sido (ifueron?) las figuras centrales del derecho privado, [...] [se ven en crisis frente a] la universalización de los intercambios, [en una crisis de identidad respecto de los nuevos paradigmas] (2014, pp. 4-7).

Dicha supremacía se plantea en términos de derechos fundamentales, cuya garantía y defensa están decididamente por encima de la autonomía de los particulares y las obligaciones que asumen en ejercicio de sus libertades. «El ejercicio legítimo de los derechos fundamentales es un privilegio que tiene origen constitucional en tanto se desprende de la propia Carta Política; no es [...] una prerrogativa de origen contractual cuyo disfrute pueda estar sometido al cumplimiento de las obligaciones surgidas de una convención privada» (Acción de tutela instaurada por Juan Gustavo Rua Cardona con respecto al derecho al trabajo, consideración 2).

Así las cosas, es un hecho destacado por la doctrina que la mayor influencia de los valores constitucionales pone en evidencia un nuevo papel de la Constitución también en el campo del derecho de las obligaciones, en especial en materia de responsabilidad civil en la forma de la tutela aquiliana (Cortés, 2009b, p. 76), pero también en la responsabilidad de contrato, para verificar que la exigencia de tutela de los derechos fundamentales pueda ser satisfecha mediante los instrumentos del derecho privado. De esta manera, los principios constitucionales asumen un carácter fuerte en el derecho privado de obligaciones, con la capacidad para influir en los procesos legislativos y judiciales (Cortés, 2009b, p. 78) de la misma forma en que orientan e influyen los procesos de armonización del derecho.

Se hará referencia, a modo de ejemplo, a principios que pueden considerarse fundamentales y relevantes para la disciplina de las obligaciones en la actualidad. Se habla de dignidad humana, igualdad, solidaridad, libertad. Como señala Édgar Cortés, estos son, además, principios constitutivos del ordenamiento jurídico, «y aunque su contenido está condicionado por el contexto cultural del que emanan y en el que se aplican, lo cierto es que ellos son portadores de un carácter, y su presencia comporta una "toma de posición" frente a todas las situaciones en que se ponga en juego una "cuestión de principio"» (2009b, p. 80). Se trata pues de una función recíproca de complemento

NOTAS SOBRE

ALGUNOS

PRINCIPIOS

GENERALES

DEL DERECHO:

UNA REFLEXIÓN

A PARTIR DE

PRINCIPIOS

GENERALES Y

SU INFLUENCIA

EN LAS

OBLIGACIONES EN

LA EXPERIENCIA

JURÍDICA

COLOMBIANA

NOTES ABOUT

SOME GENERAL

PRINCIPLES OF

LAW: A VIEW OF

SOME GENERAL

PRINCIPLES AND

THEIR INFLUENCE

ON THE LAW OF

OBLIGATIONS

IN COLOMBIAN

LEGAL

EXPERIENCE 
la que cumplen los principios constitucionales respecto de las reglas del derecho privado, en particular en la disciplina de las obligaciones, que viene así a integrarse con el carácter fuerte de estos principios, alargando la lista tradicionalmente considerada. Esta idea se encuentra en relación con un principio de reciprocidad en las relaciones individuo-Estado, de allí que la Corte Constitucional de Colombia haya sostenido que la dignidad humana, la solidaridad y la prevalencia del interés general sean principios fundamentales de la organización política del Estado social de Derecho en el marco de las relaciones entre los ciudadanos y ninguna interpretación puede negar o anular estos principios de jerarquía constitucional. Así lo ha dicho la Corte Constitucional:

En aras de la primacía del interés general las autoridades no pueden desconocer el principio de la dignidad humana ni deducir del deber de solidaridad obligaciones que rompen los principios de equilibrio en las cargas públicas (CP artículo 13) o de reciprocidad en las relaciones entre el individuo y el Estado (CP artículos 2, 5 y 6).

Las autoridades están instituidas para proteger los derechos y libertades de todas las personas residentes en Colombia y asegurar el cumplimiento de los deberes sociales del Estado y los particulares (CP artículo 2). El reconocimiento de la primacía de los derechos inalienables de la persona (CP artículo 5) constituye un límite sustancial en el desarrollo de la misión encomendada por la Constitución a las autoridades. Es por ello que el Estado, al hacer efectivo el cumplimiento de un deber u obligación social, debe asegurar previamente que su actuación no vulnere derechos fundamentales de las personas. Los particulares no son responsables (CP artículo 6) por rehusarse a cumplir una obligación manifiestamente injusta e ilegítima. Este sería el caso si el Estado, pese a no garantizar la protección material de la familia, hiciera exigible una obligación a una persona de la que depende el sostenimiento de los hijos, sin tomar en consideración que en las circunstancias concretas se exponen y arriesgan gravemente los derechos fundamentales reconocidos en la propia Constitución como prioritarios (Acciones de tutela instauradas por Nelcy Johana Marín Sanabria e Ingrid Jhoana Chávez Coronado contra la Sexta Brigada Distrito Militar de Reclutamiento Ibagué y el Comandante del Batallón Jaime Rooke, consideración 4.3).

El factor determinante de esta nueva comprensión de la relación obligatoria está constituido por la eficacia directa de los derechos fundamentales en las relaciones privadas, y la necesaria determinación del núcleo esencial del derecho y el ámbito de su posible vulneración, como lo ha señalado la Corte Constitucional:

Entre los particulares el contenido de un derecho fundamental, no siempre se plantea en idénticos términos a los referidos en los casos en los que el Estado es el sujeto que perpetra la lesión. La doctrina de la 
eficacia directa de los derechos fundamentales en las relaciones privadas, cuando ello es posible, debe proponerse mostrar cómo y en qué sentido el elemento fundamental de un derecho puede resultar específicamente vulnerado (Acción de tutela instaurada por Marcelino Rodríguez Rojas con respecto a la eficacia directa de los derechos fundamentales frente a particulares..., fundamento 5).

La influencia del constitucionalismo es innegable, las decisiones de la Corte Suprema de Justicia (CSJ) en sala de Casación civil no solo mencionan los artículos de la Constitución, sino que también mencionan decisiones de la Corte Constitucional. Así, también sucede con las referencias a la Convención Americana de los Derechos Humanos (véase, por ejemplo, la Sentencia del 05 de agosto de 2014). Se encuentra la referencia puntual a los principios constitucionales y, como se dijo, a los artículos de la Constitución y a las decisiones constitucionales; en ocasiones las referencias son implícitas y se deducen con facilidad.

Acá se reflexiona en relación con la obligación como institución jurídica unitaria que no ha dejado de ser un vínculo de garantía, un vínculo que implica latente una responsabilidad. Ella es una relación jurídica compleja, es organismo, estructura y proceso (véase Morales Hervias, 2013, p. 57); ella es una expectativa de prestación conferida al acreedor; esto es, en ejercicio de la autonomía privada, los contratantes vinculan el incumplimiento de la expectativa con la consecuencia jurídica de la realización de la responsabilidad (Betti, 2015, p. 252). Por ello, el débito es un deber de cumplimiento condicionado, impuesto positivamente por una norma jurídica, o por la particular naturaleza dinámica de los negocios jurídicos, o por el daño injusto, o por el enriquecimiento torticero (véase Hinestrosa, 2015, pp. 55ss.).

Se enunciarán apenas algunos principios sobre los cuales se ha escrito mares de tinta, no se pretende ser exhaustivos ni abarcar la bibliografía sin confines en esta materia, se pretende solamente proponer un elenco de algunos de los principios más relevantes para mejor sistematizar y organizar el conocimiento del derecho, y avanzar en su armonización y su mejoramiento cotidiano. Es un elenco abierto a partir de la experiencia colombiana, en todo sentido, para que los colegas lo colmen con sus aportes.

\section{PRINCIPIO DE LIBERTAD}

La libertad individual es una manera en la que el particular discierne sobre su propia persona para desarrollar sus iniciativas, tender al mejoramiento de sí mismo y de la especie; por ello, la libertad debe ser ejercida en beneficio propio y en beneficio del otro, pero también del progreso colectivo (véase Hinestrosa, 2015, p. 118; asimismo, Constitución Política de Colombia, artículo 16). Se trata de la libertad

NOTAS SOBRE

ALGUNOS

PRINCIPIOS

GENERALES

DEL DERECHO:

UNA REFLEXIÓN

A PARTIR DE

PRINCIPIOS

GENERALES Y

SU INFLUENCIA

EN LAS

OBLIGACIONES EN

LA EXPERIENCIA

JURÍDICA

COLOMBIANA

NOTES ABOUT

SOME GENERAL

PRINCIPLES OF

LAW: A VIEW OF

SOME GENERAL

PRINCIPLES AND

THEIR INFLUENCE

ON THE LAW OF

OBLIGATIONS

IN COLOMBIAN

LEGAL

EXPERIENCE 
como una elección libre del «verdadero» yo, aunque a menudo esté oculto y no articulado. Para Isaiah Berlin, la libertad consiste en ser dueño de uno mismo, que los demás no me impidan decidir cómo quiero. Pero ¿hasta dónde puede llegar la interferencia de los demás? ¿Con qué motivos se justifica la interferencia de otros? Se trata del problema de la legitimidad de la interferencia, ¿qué razones, respeto por la constitución y la ley?, iel orden público?, iel apoyo al modelo institucional?, ¿al modelo económico?, ial interés general?, iservicio público?, idignidad humana? Y cuando hablamos de obligaciones jurídicas, iellas son una expresión de la libertad o son límite de esta?

Resulta ilustrativo que Montesquieu diga que no hay palabra que haya recibido tantos significados diferentes como la de «libertad». Algunos la han entendido como la facultad de eliminar un poder tiránico; otros, como el poder de decidir a quién obedecer; otros, como el derecho a estar armado y poder actuar violentamente; otros, en fin, como el privilegio de no ser gobernados sino por un hombre de la propia nación y por sus propias leyes (Montesquieu, 1869, p. 140).

El concepto de libertad es tan amplio que hay pocas interpretaciones que no se le ajusten. Pero podemos referir, junto con Berlin, dos sentidos del concepto: el primero, como libertad negativa, hasta dónde se permite que personas o grupos de personas hagan o estén sin la interferencia de otras personas. El segundo, como libertad positiva, qué o quién es la causa del control o la interferencia que puede establecer que alguien haga o sea una cosa u otra (Berlin, 1993, pp. 15ss; el mismo Berlin también se refiere a Bentham, quien continuó diciendo tenazmente que la ley no liberaba sino que restringía: «Toda ley es una violación de la libertad», incluso esa «infracción» conduce a un «aumento de la libertad total»).

La libertad, como la justicia, la igualdad, la dignidad y otros principios y valores, no pueden observarse mientras su contenido no se especifique al mismo tiempo. Pero ies una invención moral del hombre? iEs un hecho de su inteligencia resultante de la vida ética que le pertenece como especie? Seguramente no es un instinto, como el miedo, la supervivencia. Tiene una condición semántica de «macrovalor», de «macrocategoría» que explica el amplio margen de ambigüedad que mantiene el concepto de libertad. Rousseau argumentó que se debía «obligar al hombre a ser libre» para hacerlo ajustarse a la voluntad general. Este razonamiento del ginebrino es rechazado hoy por Isaiah Berlin, el conocido teórico, ya que según Berlin una cosa no puede ser y al mismo tiempo ser su opuesto (contradictio in adiecto); es decir, la reducción de la libertad no puede ser libertad, esto no es otra cosa que la ausencia de opresión.

Pero, si la justificación de los límites que el orden jurídico impone a nuestra libertad tiene sus raíces en una transacción razonable entre 
valores similares, entonces necesitamos el orden jurídico del Estado no porque nos libere, sino porque, incluso si produce lo contrario con sus prohibiciones (precisamente Nietzsche observa en la libertad un concepto servil por la relación conceptual que existe entre libertad y esclavitud), nos hace menos violentos y, en este sentido, más igualitarios y justos viviendo en sociedad. En esto consiste la afirmación de Rousseau según la cual el ciudadano debe ser forzado a ser libre (Flórez, 2015, p. 3).

Del gran principio pro libertate, derivan las libertades públicas y privadas con cuyo ejercicio los ciudadanos se mueven en las distintas realidades económica, política y social. En materia de obligaciones, la libertad es el primer principio de la obligación con fuente lícita - porque el cumplimiento de la obligación históricamente ha sido un hecho voluntario del deudor (véase Betti, 2015, passim; Grosso, 2011, p. 9)_a pesar de la dificultad para establecer sus contornos. Para contraer obligaciones negociales, es menester gozar de libertad negocial: libertad de escoger el tipo negocial, libertad de escoger el contenido, libertad de escoger a la parte contractual o negocial. Con respecto al principio de libertad, mucho se puede argumentar en derecho privado, basta señalar la libertad negocial y su amplia relevancia, la libertad de empresa, o la aplicación de la libertad en materia probatoria, o su relación con el formalismo y el neoformalismo en los contratos.

La libertad contractual se refiere a aquella libertad que el ordenamiento jurídico otorga a los ciudadanos para celebrar acuerdos que dentro de cierto marco legal podrán tener validez y ser exigibles judicialmente (véase Kötz \& Flessner, 1997, pp. 124ss.). Es decir, los particulares ejercen su autonomía dentro del amplio margen del ordenamiento. Para tales efectos de programación de los propios intereses jurídico-patrimoniales, se exige que el interés particular sea socialmente útil, relevante, reconocido por la sociedad como merecedor de tutela por parte del ordenamiento jurídico. Esta libertad no puede entenderse como arbitrio sin límites en la programación de sus relaciones contractuales. Se trata más bien de una libertad de ejecutar las propias iniciativas y escogencias dentro del mercado (véase Bianca, 2000, p. 31; quien también señala cómo la actividad negocial se enmarca dentro de una realidad socioeconómica que la condiciona. No obstante, la realidad económica debe entenderse también ella enmarcada dentro del marco constitucional o, mejor, la Constitución es el telón de fondo, y la exigencia de conformidad con su texto y su espíritu debería condicionar el proceso productivo, la actividad económica).

En relación con la libertad de las partes en la elección de las formas, se trata de un cambio proclamado por el derecho civil moderno (para una perspectiva desde la armonización del derecho latinoamericano, véase

NOTAS SOBRE

ALGUNOS

PRINCIPIOS

GENERALES

DEL DERECHO:

UNA REFLEXIÓN

A PARTIR DE

PRINCIPIOS

GENERALES Y

SU INFLUENCIA

EN LAS

OBLIGACIONES EN

LA EXPERIENCIA

JURÍDICA

colombiana

NOTES ABOUT

SOME GENERAL

PRINCIPLES OF

LAW: A VIEW OF

SOME GENERAL

PRINCIPLES AND

THEIR INFLUENCE

ON THE LAW OF

OBLIGATIONS

IN COLOMBIAN

LEGAL

EXPERIENCE 
Morales Moreno, 2014; Momberg, 2018; Momberg \& Vogenauer, 2017), en oposición a la excesiva acción tutelar del derecho romano, pero tal libertad encuentra límites en la exigencia de precisión y certidumbre en los pactos, por lo que se establecen solemnidades especiales para ciertos contratos, en los que la forma es condición para su validez jurídica.

Como por encima del interés particular de las personas se hallan el interés general de la sociedad que requiere precisión y certidumbre en los pactos, la ley ha establecido solemnidades especiales para ciertos contratos que por su importancia económica deben quedar a cubierto de dudas y rectificaciones posteriores. Esta necesidad ha impuesto límites al principio fundamental de la libertad de las partes en la elección de las formas, principio proclamado por el derecho civil moderno, en oposición a la excesiva acción tutelar del derecho romano, cuya injerencia en los negocios privados prácticamente había anulado la voluntad individual. Por eso hay contratos en que la forma es condición de su existencia, y no puede ser omitida ni alterada sin perder su validez jurídica (Sentencia del 24 de octubre de 1957).

El principio de libertad de configuración negocial, el principio de libertad contractual que regula fundamentalmente las relaciones entre hombres por naturaleza libres, afirma una «libertad de configurar el contenido de los contratos, con las solas limitaciones que establezcan, de manera expresa, normas imperativas; y, por supuesto, respetar la autonomía privada, de forma tal que una vez expresada en cláusulas libremente asentidas, ellas, como la ley, hagan imperio, sin posibilidad de eludir su aplicación» (Sentencia del 06 de julio de 2007, consideración III, B, 1). Y así en muchas otras decisiones de Casación civil (entre muchos otros fallos, véase, para el caso colombiano: Sentencia del 12 de setiembre de 2000; Sentencia del 19 de diciembre de 2005; Sentencia del 01 de diciembre de 2008; Sentencia del 27 de julio de 2015). La armonización del derecholatinoamericano se ha ocupadode este principio en materia de contratos, lo consagra en el artículo 5 de los Principios latinoamericanos de Derecho de los Contratos (PLDC): las partes son libres para celebrar contratos y para determinar su contenido, no siendo contra el orden público o la ley (véase, en la perspectiva de la armonización, Momberg \& Vogenauer, 2017, passim; Momberg, 2018). Asimismo, el artículo 10 de los PLDC establece la libertad en las negociaciones entre las partes del contrato y puntualiza que son las partes ellas mismas libres de negociar el contrato y de retirarse en cualquier momento, pero esto y aquello deben hacerlo conforme a la buena fe.

Por su parte el GADAL hace referencia a la libertad en el artículo 6 del Código Marco de Obligaciones para América Latina con la rúbrica de dignidad de la persona humana y derechos fundamentales. La norma de armonización propone que la dignidad de la persona humana y la tutela 
de sus derechos fundamentales, especialmente la libertad, la igualdad y el principio de no discriminación rigen el surgimiento, cumplimiento, interpretación y extinción de las obligaciones.

Por su parte, en materia de responsabilidad contractual, se ha hecho mención de la limitación al principio de libertad que las partes tienen de fijar el monto de la responsabilidad, sobre la prohibición de la ley comercial a este respecto, que sanciona con ineficacia de pleno derecho las estipulaciones contrarias a los topes imperativos (véase, por ejemplo, Sentencia del 08 de setiembre de 2011). También en las decisiones de la Casación civil, se hace mención del principio de libertad, por ejemplo, en materia de la libre apreciación de la prueba (Sentencia del 15 de julio de 2004), y de libertad probatoria (Sentencia del 28 de agosto de 2015).

En particular sobre la libertad negocial, es algo obvio que exista una libertad fundamental de los particulares para escoger el tipo contractual más acorde con sus intereses y la finalidad perseguida. No obstante, esta libertad no se configura de forma ilimitada. Finalmente es el juez quien realiza la operación hermenéutica de tipificar la operación, y bien puede separarse de la calificación proyectada por las partes (D’Amico, 1993, pp. 129ss.). El hecho de que no haya un nomen iuris para determinado programa de intereses que las partes aspiran recoger en un tipo contractual no constituye un límite a la libertad negocial en sentido propio, pero en cambio sí lo es el hecho de que deba haber correspondencia entre el interés fundamental perseguido en concreto por las partes y el intento práctico para cuya satisfacción el esquema negocial escogido parece ser el instrumento idóneo (D’Amico, 1993, pp. 131ss.).

El ordenamiento jurídico fija el marco dentro del cual las partes en ejercicio de su libertad negocial en la forma de autonomía privada programan los propios intereses. Luego recoge la realidad de los tipos socialmente definidos y les confiere efectos jurídicos. Se trata del reconocimiento de un interés práctico merecedor de protección jurídica, socialmente útil, en última instancia, reconocimiento y protección de cierta libertad de configuración de los particulares.

La libertad acá está en relación con la autonomía privada vista como expresión de la libertad negocial o contractual (Fabre-Magnan, 2004, pp. 49ss.). El principio y dimensión de la libertad están en innegable relación con la autonomía privada, pues para el ejercicio de esta y para sus proyecciones es menester un cierto ámbito o una cierta esfera de libertades individuales. La libertad contractual debe estar en concordancia práctica con la garantía constitucional para alcanzar el contrato justo (Becker, 2003, p. 4; véase también Benítez Caorsi, 2013, p. 87).

NOTAS SOBRE

ALGUNOS

PRINCIPIOS

GENERALES

DEL DERECHO:

UNA REFLEXIÓN

a pARTIR DE

PRINCIPIOS

GENERALES Y

SU INFLUENCIA

EN LAS

OBLIGACIONES EN

LA EXPERIENCIA

JURÍDICA

COLOMBIANA

NOTES ABOUT

SOME GENERAL

PRINCIPLES OF

LAW: A VIEW OF

SOME GENERAL

PRINCIPLES AND

THEIR INFLUENCE

ON THE LAW OF

OBLIGATIONS

IN COLOMBIAN

LEGAL

EXPERIENCE 


\section{PRINCIPIO DE DIGNIDAD HUMANA}

Principio fundamental del orden jurídico de nuestro tiempo es la dignidad humana (Constitución Política, artículo 1). Se trata de un principio fundante robusto y extenso que exige la posición central de la persona humana en la experiencia jurídica: «En línea con las Constituciones políticas más modernas, que tienen a la persona como protagonista de toda su regulación, Colombia se concibe como un Estado Social de Derecho, sustentado, entre otras bases, en el respeto de la dignidad humana, la solidaridad y la igualdad de las personas» (Koteich Katib, 2012, pp. 308ss.). En el mismo sentido, Carvajal Sánchez habla de un proceso de institucionalización de la dignidad humana y, a su vez, señala cómo «debe recordarse que la dignidad de la persona humana es un concepto de origen extra-jurídico que progresivamente ha sido objeto de varias normas jurídicas hasta llegar a reconocerse como una norma constitucional de principio» (2012, pp. 35ss.; véase también 2013). La persona debe ser el fin del Estado y del derecho, y su dignidad compromete a los poderes públicos, en particular al juez en la interpretación y aplicación de las normas, como indican las siguientes sentencias de la Corte Constitucional de Colombia:

cuando el Estado, independientemente de cualquier consideración histórica, cultural, política o social, establece normas sustanciales o procedimentales dirigidas a regular las libertades, derechos o deberes del individuo, sin tener presente el valor superior de la dignidad humana, serán regulaciones lógica y sociológicamente inadecuadas a la índole de la condición personal del ser humano y, por contera, contrarias a la Constitución, en la medida en que se afectarían igualmente los derechos fundamentales, dado que estos constituyen condiciones mínimas para la «vida digna» del ser humano; en efecto, cuando se alude a los derechos fundamentales se hace referencia a aquellos valores que son anejos a la dignidad humana (Demanda de inconstitucionalidad contra el parágrafo del artículo 164 del decreto ley 1344 de 1970, Código Nacional de Tránsito Terrestre, consideración 2.1).

En nuestro ordenamiento jurídico se consagra la dignidad humana como fundamento esencial que deben observar todas las autoridades sobre sus actuaciones, en especial la de los servicios públicos esenciales como la salud, cuya prestación deben garantizar (Acción de tutela presentada por Angie Daniela Salazar Zapata c. Coomeva EPS, consideración 3.2.3).

A propósito señala Santaella lo siguiente:

El marcado compromiso estatal con la promoción de condiciones materiales aptas para la realización del principio de dignidad humana y del conjunto de los derechos fundamentales que acompaña a esta fórmula así permite inferirlo. Su empeño en la instauración de un orden económico y social justo, vertebrado en valores supremos como la 
convivencia, la libertad, la justicia, la igualdad, el conocimiento y la paz (Preámbulo CC), y principios como la dignidad, el trabajo, la solidaridad, la prevalencia del interés general (artículo 1 CC), la democracia (artículo 3 idem), la supremacía normativa de la Constitución (artículo 4 ibídem) y la primacía de los derechos inalienables de la persona (artículo 5 idem), que procure y asegure a todos condiciones de vida digna en forma de acceso efectivo a los bienes y servicios básicos (artículo 334 párr. 2 CC), representa algo más que una simple declaración provista de un fuerte sentido retórico, pero carente de efectos jurídicos prácticos. Constituye el camino definido para la realización plena de su finalidad, cuyo centro es la persona humana, no en abstracto, sino propendiendo por su integración y participación en la sociedad de la cual hace parte. De ahí que los derechos fundamentales consagrados se erijan en guías, a la vez que en límites, de la acción del Estado y de los gobernantes.

En tanto que parte integrante de este sistema, la configuración positiva del derecho de propiedad resulta igualmente limitada y permeada tanto por el Estado social, como por el conjunto de principios, valores y derechos fundamentales que le rodean y que encuentran cabida dentro del orden axiológico definido por la Constitución. Producto de esta interacción, la propiedad reafirma y potencia el papel de instrumento al servicio del Estado social y la realización de sus cometidos que le es atribuido por su módulo colectivo o social. Gracias a esta circunstancia, este derecho opera de tal forma que ofrece la posibilidad de hacer efectivos principios como la dignidad humana, la libertad y la solidaridad, así como de realizar derechos tales como la igualdad, la intimidad, el libre desarrollo de la personalidad, la vivienda digna, el medio ambiente sano, el acceso a la cultura y al conocimiento y la libre competencia económica. Todo ello mediante la recepción y ejecución de directrices institucionales que, emanadas de estos últimos, tienen por objetivo hacer que los derechos patrimoniales satisfagan en mayor grado y en mayor número las necesidades de los asociados (2010, pp. 75-76; véase también Upegui Mejía, 2009, p. 18, para quien la construcción del concepto de Estado social de Derecho en Colombia ha tenido un carácter autónomo y singular, propio de la cultura jurídica colombiana).

En la disciplina de las obligaciones, «la responsabilidad civil no ha escapado al influjo de esa renovada atención que gira alrededor de los derechos constitucionales fundamentales, la dignidad en particular, lo que la ha llevado a ampliar sus horizontes y a intentar buscar mecanismos que le permitan una mayor aproximación al principio de reparación integral del daño» (Koteich Katib, 2012, pp. 308ss.). En particular, la dignidad humana «constituye un elemento fundamental para la construcción de un modelo de reparación de los daños a la persona» (Cortés, 2009b, p. 85). Asimismo, Cortés puntualiza que

\section{NOTAS SOBRE \\ ALGUNOS \\ PRINCIPIOS \\ GENERALES \\ DEL DERECHO: \\ UNA REFLEXIÓN \\ a PARTIR DE \\ PRINCIPIOS \\ GENERALES Y \\ SU INFLUENCIA \\ EN LAS}

OBLIGACIONESEN

LA EXPERIENCIA

JURÍDICA

COLOMBIANA

NOTES ABOUT

SOME GENERAL

PRINCIPLES OF

LAW: A VIEW OF

SOME GENERAL

PRINCIPLES AND

THEIR INFLUENCE

ON THE LAW OF

OBLIGATIONS

IN COLOMBIAN

LEGAL

EXPERIENCE 
la dignidad humana representa el núcleo primario y esencial del individuo, núcleo que le permite expresarse y desenvolverse con plenitud dentro de la sociedad; así, de la confrontación con el principio de dignidad derivan su fundamento todos los derechos que se pueden estimar como inviolables, pues la calificación de un interés de la persona como inviolable supone que el interés en cuestión tenga una relevancia capaz de comprometer o involucrar de manera determinante el principio de dignidad (p. 85).

Se habla tradicionalmente de constitucionalización del derecho privado para referirse a la aplicación directa de los derechos fundamentales, de los principios y normas constitucionales en relación con el derecho privado, y el efecto de tales normas y principios sobre la disciplina de las obligaciones (Franco Victoria, 2011).

Ahora bien, la dignidad humana, desde el punto de vista de su naturaleza jurídica, se considera una entidad normativa que puede observarse «a partir de su objeto concreto de protección y a partir de su funcionalidad normativa» (Acciones de tutela instauradas por Austreberto de Ávila Ríos y otros, y Edwin Campo Vega (personero de El Arenal (Bolivar)) contra Electrocosta S.A., consideración 10).

Vista desde su objeto concreto de protección, la dignidad humana en la jurisprudencia de la Corte Constitucional presenta tres lineamientos claros y diferenciables:

(i) La dignidad humana entendida como autonomía o como posibilidad de diseñar un plan vital y de determinarse según sus características (vivir como quiera). (ii) La dignidad humana entendida como ciertas condiciones materiales concretas de existencia (vivir bien). Y (iii) la dignidad humana entendida como intangibilidad de los bienes no patrimoniales, integridad física e integridad moral (vivir sin humillaciones). (Acciones de tutela instauradas por Austreberto de Ávila Ríos y otros, y Edwin Campo Vega (personero de El Arenal (Bolivar)) contra Electrocosta S.A., consideración 10).

Considerada respecto de su funcionalidad como enunciado normativo, se la ha identificado con tres lineamientos: «(i) la dignidad humana entendida como principio fundante del ordenamiento jurídico y por tanto del Estado, y en este sentido la dignidad como valor. (ii) La dignidad humana entendida como principio constitucional. Y (iii) la dignidad humana entendida como derecho fundamental autónomo» (Acciones de tutela instauradas por Austreberto de Ávila Ríos y otros, y Edwin Campo Vega (personero de El Arenal (Bolívar)) contra Electrocosta S.A., consideración 10). Considérese también la sentencia de la Corte en el caso Acción de tutela presentada por Angie Daniela Salazar Zapata c. Coomeva EPS: 
La jurisprudencia de esta Corporación, desde sus inicios ha señalado la dignidad humana, como entidad normativa que puede comprender tres objetos concretos de protección: (i) la autonomía o posibilidad de diseñar un plan vital y de determinarse según sus características (vivir como se quiera); (ii) la presencia de ciertas condiciones materiales concretas de existencia (vivir bien) y (iii) la intangibilidad de los bienes no patrimoniales, integridad física e integridad moral (vivir sin humillaciones).

La Corte Constitucional ha reiterado que la dignidad humana como derecho fundamental, implica la facultad de exigir su realización en los ámbitos a los que atañe y el deber de propiciarlos; como principio, se entiende como uno de los fundamentos del Estado Social de Derecho; y, finalmente como valor, representa un ideal de corrección que al Estado le corresponde preservar (consideración 3.2.3).

Ahora conviene preguntarse cómo se integra el objeto protegido por los enunciados normativos de la Constitución que desarrollan el concepto de dignidad humana, en otras palabras, cuál es el contenido material de este principio superior. El referente concreto de la dignidad humana, o bien, su contenido material, está vinculado, según la Corte Constitucional, con tres ámbitos exclusivos de la persona natural que evidentemente involucran la disciplina de las obligaciones: «la autonomía individual (materializada en la posibilidad de elegir un proyecto de vida y de determinarse según esa elección), unas condiciones de vida cualificadas (referidas a las circunstancias materiales necesarias para desarrollar el proyecto de vida) y la intangibilidad del cuerpo y del espíritu (entendida como integridad física y espiritual, presupuesto para la realización del proyecto de vida)»(Acciones de tutela instauradas por Austreberto de Ávila Ríos..., consideración 16). En materia de garantía constitucional y derecho al libre desarrollo de la personalidad, tómese en cuenta la siguiente sentencia:

La Corte Constitucional tomando como punto de partida los principios fundamentales de nuestro Estado Social de Derecho, previstos en el artículo $1^{\circ}$ de la Carta, ha abordado y catalogado el derecho a la dignidad humana como de raigambre fundamental en tanto que el texto superior señala que Colombia está fundada en el respeto a esta, por lo que ha reconocido su estatus de manera autónoma. Tal derecho se encuentra muy arraigado a otras garantías constitucionales, destacándose, entre ellas, el derecho a la intimidad personal y al libre desarrollo de la personalidad. Con relación a este último se ha indicado por esta Corte que con sustento en lo dispuesto por el artículo 16 de la Carta Política, se debe reconocer en cabeza de todas las personas con estatus de fundamental. Así pues, esta corporación en reiterados pronunciamientos, ha enfatizado que la referida valoración permite considerar al hombre como un ser único, director de su vida y responsable

NOTAS SOBRE

ALGUNOS

PRINCIPIOS

GENERALES

DEL DERECHO:

UNA REFLEXIÓN

A PARTIR DE

PRINCIPIOS

GENERALES Y

SU INFLUENCIA

EN LAS

OBLIGACIONESEN

LA EXPERIENCIA

JURÍDICA

COLOMBIANA

NOTES ABOUT

SOME GENERAL

PRINCIPLES OF

LAW: A VIEW OF

SOME GENERAL

PRINCIPLES AND

THEIR INFLUENCE

ON THE LAW OF

OBLIGATIONS

IN COLOMBIAN

LEGAL

EXPERIENCE 
de sus decisiones y actos solo sujeto a ciertas limitaciones orientadas a preservar los derechos de los demás y mantener el orden jurídico. A partir del derecho al libre desarrollo de la personalidad se desprende la posibilidad de que cada ser humano pueda trazar su proyecto de vida de acuerdo a sus deseos, anhelos, intereses y convicciones, el cual debe ser respetado y no se puede, por ende, coartar su desarrollo como quiera que ha surgido de la esfera privada del ser humano y constituye su identidad como individuo, salvo en las excepciones descritas previamente, habida cuenta que ello asegura unas condiciones de igualdad y de dignidad (Leonardo David Mizzar Vargas c. Policía Metropolitana de Barranquilla, resumen).

Para la Corte estos tres ámbitos de protección integran, entendidos en su conjunto, el objeto protegido por las normas constitucionales desarrolladas a partir de los enunciados normativos sobre «dignidad». Se trata, en palabras de la misma Corte, de «una concepción normativista o funcionalista en el sentido de completar los contenidos» del enunciado «con los propios de la dimensión social de la persona humana» (Acciones de tutela instauradas por Austreberto de Ávila Ríos..., consideración 29). En el dicho de la Corte, esto sería importante al menos por tres razones:

primero, porque permite racionalizar el manejo normativo de la dignidad humana, segundo, porque lo presenta más armónico con el contenido axiológico de la Constitución de 1991, y tercero, porque abre la posibilidad de concretar con mayor claridad los mandatos de la Constitución.

[...] los ámbitos de protección de la dignidad humana deberán apreciarse no como contenidos abstractos de un referente natural, sino como contenidos concretos, en relación con las circunstancias en las cuales el ser humano se desarrolla ordinariamente (consideración 29).

Resulta obvio, entonces, que en materia de obligaciones debe tener plena eficacia el principio de dignidad humana, tanto en las obligaciones de fuente lícita como en aquellas que nacen del daño extracontractual. Y, en estrecha relación con la dignidad, se presenta la tutela de la salud, la idea de ese núcleo ineludible de daño resarcible siempre y en toda circunstancia, esa tutela de la salud que se erige como principio constitucional y que tiene relevancia fundamental en las relaciones privadas de consumo. Así que, cualquier modelo de reparación del daño no puede no tener en cuenta el principio de dignidad humana y la tutela de la salud que le corresponde como figura autónoma (véase Cortés, 2009b, p. 87; quien, a su vez, sobre la tutela a la salud como principio constitucional, puntualiza cómo dicha tutela no deba entenderse «solo como la obligación del Estado de procurar asistencia al individuo que padece una enfermedad, sino también la pretensión de cada cual de ver 
que las condiciones propias de su salud no se vean alteradas por el obrar de cualquier otra persona»).

En cuanto al principio fundante del respeto por la dignidad humana, en decisiones recientes la Casación civil destaca que este principio trasciende la noción de derecho subjetivo e ilumina toda la estructura normativa del Estado. Es decir, se trata de un principio rector del catálogo de garantías y derechos consagrados en la Carta política, que encuentra su base en la libertad e identidad del individuo. Este principio está ligado indefectiblemente al de solidaridad social, y así también lo ha señalado la Corte suprema en sede de Casación civil (véase Sentencia del 09 de setiembre de 2015). En ocasiones no lo desarrolla con cita puntual, sino que más bien hace referencia general a él como principio base del Estado, en relación con el libre desarrollo de la personalidad (como, por ejemplo, en la Sentencia del 09 de diciembre de 2011).

En cuanto a la responsabilidad civil, también la Casación civil ha hecho mención del respeto por la dignidad humana, en especial en lo que tiene que ver con la reparación integral del daño como reconocimiento del valor de la persona humana que eventualmente haya sido agredida en su dignidad. Esta idea ha sido reconocida por la jurisprudencia desde el año 1922 (en la conocida Sentencia del 21 de julio de 1922, en la causa de León Villaveces contra el Municipio de Bogotá), y se reconoce aún hoy en cuanto la persona que padece un daño puede verse ofendida en su honra o en su dignidad personal (véase Sentencia del 05 de agosto de 2014). La Casación civil ha precisado lo siguiente:

Con todo, la defensa del principio supremo de la dignidad humana mediante el resarcimiento integral del perjuicio que se ocasiona a los bienes más preciados para el individuo, es una institución del derecho civil, y como tal, requiere para su concesión del cumplimiento de los requisitos de esta clase de responsabilidad (Sentencia del 05 de agosto de 2014, consideración 6).

La reparación del daño no patrimonial, por el contrario, no cumple una función resarcitoria en sentido estricto, pues ningún bien material es equiparable al valor absoluto de la dignidad humana, el cual es, por lo tanto, irremplazable (consideración 7).

\section{PRINCIPIO DE IGUALDAD}

La palabra igualdad es conceptualmente ambigua. Si bien es cierto que el concepto de igualdad puede ser unitario, también es cierto que la expresión igualdad tiene varios sentidos en el lenguaje común; es decir, tiene un significado particular al tiempo que diversos significados. Lo mismo decimos de la desigualdad: es al mismo tiempo un concepto como una multitud de concepciones (López Roca, 2012, p. 64).

NOTAS SOBRE

ALGUNOS

PRINCIPIOS

GENERALES

DEL DERECHO:

UNA REFLEXIÓN

A PARTIR DE

PRINCIPIOS

GENERALES Y

SU INFLUENCIA

EN LAS

OBLIGACIONES EN

LA EXPERIENCIA

JURÍDICA

COLOMBIANA

NOTES ABOUT

SOME GENERAL

PRINCIPLES OF

LAW: A VIEW OF

SOME GENERAL

PRINCIPLES AND

THEIR INFLUENCE

ON THE LAW OF

OBLIGATIONS

IN COLOMBIAN

LEGAL

EXPERIENCE 
La igualdad es invariablemente un acto de equiparación, afirma Kaufmann, y este acto no reposa solo en conocimiento racional, sino que significa, especialmente, una decisión, un poder. Igualdad es abstracción de desigualdad; y esta, a su vez, es abstracción de igualdad (Kaufmann, 1999, p. 295). La igualdad es un principio formal, establece que lo igual debe ser tratado igual, y lo desigual, análogamente, en forma desigual (Kaufmann, 1999). Si se piensa en clases de igualdad, se encuentra la distinción aristotélica que distingue dos clases de justicia dentro de las cuales se manifiesta la igualdad: la justicia compensatoria o conmutativa y la justicia de distribución o distributiva. La primera es la justicia entre los desiguales por naturaleza, pero iguales ante la ley (mercancía y precio, daño y reparación); la segunda, en cambio, se refiere a la igualdad proporcional en el tratamiento de una pluralidad de personas (la repartición de derechos y deberes conforme a medida de dignidad, capacidad, necesidad, culpa), es la forma primigenia de justicia (Kaufmann, 1999, p. 297). Igualdad es, entonces, igualdad de relaciones, algo correspondiente, algo análogo. La igualdad es la justicia en sentido estricto.

El principio de igualdad incide en la disciplina de las obligaciones en particular en lo que tiene que ver con el daño a la salud, pero también en relación con el trato paritario que debe haber en las obligaciones de contrato. En particular, sobre el daño a la salud, el principio de igualdad se refiere a la paridad de tratamiento «a todo aquel que ha sido víctima de un atentado de su integridad psicofísica», para que el resarcimiento del daño sea uniforme cuando se trate de diferentes víctimas con el mismo tipo de lesión. Resulta «evidente que la salud es uno de los aspectos de la condición humana en los que se revela como auspiciable una igualdad entre los coasociados, y de ahí que el principio se revele como fundamental en la materia» (Cortés, 2009b, p. 83). Para Cortés, el corolario lógico es que todo aquel que sufra una lesión igual a la de otra persona deberá tener, también, una reparación igual («Asunto diferente es el de establecer un mecanismo de reparación que se corresponda de manera adecuada con el interés que compromete una lesión a la salud», $2009 \mathrm{~b}$, p. 84). Se trata pues de que a los daños «esencialmente iguales» se atribuya una misma sanción en el ámbito de la responsabilidad civil, esto es, otorgar una misma cuantía en lo que hace a la liquidación del perjuicio (Koteich Katib, 2012, p. 312).

En la jurisprudencia constitucional «[1]a igualdad no consiste en la identidad absoluta, sino en la proporcionalidad equivalente entre dos o más entes, es decir, en dar a cada cual lo adecuado según las circunstancias de tiempo, modo y lugar» (Demanda de inconstitucionalidad contra los artículos 30. (parcial), 14..., consideración 3.1; véase, además, desde la perspectiva de la doctrina privatista con particular referencia al sistema financiero y a las actividades de interés público, López Roca, 2012, 
pp. 81ss.: «Más allá de ser considerara como valor o como principio, la igualdad ha sido reconocida en los textos constitucionales como un derecho fundamental [...] El derecho de igualdad es autónomo en cuanto la configuración de una violación al mismo no depende de que se desconozcan otros derechos. Pero es relacional porque no se viola sino con relación a otros derechos o intereses»). La igualdad tiene que ver directamente con una cuestión de interés general y, de allí, su prevalencia. No se trata de una discrecionalidad radical, sino tan solo de un margen razonable de acción, precisamente para que se cumpla la ley (véase Demanda de inconstitucionalidad contra los artículos 3o. (parcial), $14 \ldots)$.

La igualdad tiene un vínculo estrecho con el talante social del Estado que se expresa en la prevalencia del componente social igualitario del Estado social de Derecho. En particular, se define en su carácter de principio estructural del ordenamiento. Según Correa Henao, «[e]s menester enunciar que la igualdad desde el punto de vista jurídico se reconoce bajo dos formas diversas: como igualdad formal, esto es, igualdad ante la ley, y como igualdad material, o sea, como igualdad con la cual el derecho responde ante situaciones materiales distintas» (2009, pp. 109ss.). Es así como la Corte Constitucional ha señalado, por ejemplo, en materia de contratos, que no es posible pactar en contra de la Constitución, habría ilicitud en la prestación si alguien se obliga a cumplir un contrato violatorio de la norma superior (Acción de tutela instaurada por Jorge Isaac Escobar en contra de la cooperativa Coopserp). En los negocios hay una igualdad formal entre las partes, pero en términos constitucionales materiales debe haber también una igualdad funcional que se entienda como expresión de la autonomía contractual y como protección de la misma en clave de igualdad (Franco Victoria, 2011, p. 239).

Se trata, entonces, de que en las obligaciones de contrato y en las obligaciones con ocasión del daño extracontractual, vista la cuestión también con el filtro de la doctrina constitucional, se prohíba, por ejemplo, en los contratos, cualquier diferenciación por razones de sexo, raza, origen nacional o familiar, lengua, religión, opinión política o filosófica, entre otras. De igual forma, implica que se liquide en términos paritarios un perjuicio sufrido por una persona y que sea igual al de otra, es decir, una reparación igual y uniforme (Acción de Tutela instaurada por Shirley Mireya Ospitia Hernández contra La Empresa METROAGUA S.A. E.S.P.).

En relación con la igualdad, la Casación civil se ha ocupado de señalar, por ejemplo, el principio de igualdad entre los hijos. En general, la Casación civil ha indicado la naturaleza de este principio en virtud del cual los casos iguales no deben ser resueltos de manera distinta por un

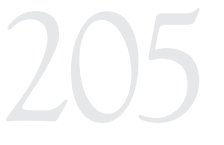

NOTAS SOBRE

ALGUNOS

PRINCIPIOS

GENERALES

DEL DERECHO:

UNA REFLEXIÓN

A PARTIR DE

PRINCIPIOS

GENERALES Y

SU INFLUENCIA

EN LAS

OBLIGACIONES EN

LA EXPERIENCIA

JURÍDICA

COLOMBIANA

NOTES ABOUT

SOME GENERAL

PRINCIPLES OF

LAW: A VIEW OF

SOME GENERAL

PRINCIPLES AND

THEIR INFLUENCE

ON THE LAW OF

OBLIGATIONS

IN COLOMBIAN

LEGAL

EXPERIENCE 
mismo juez, y se erige en mecanismo de control de la actividad judicial, y se le vincula al respeto por el denominado «precedente judicial», que le impone a los jueces una mínima racionalidad que los obliga a resolver el problema jurídico planteado de una manera que estarían dispuestos a aceptar en otro caso diferente pero con caracteres análogos. Empero, no sin destacar que esto tiene un valor relativo en virtud de la autonomía e independencia judicial consagrada en el artículo 228 de la Constitución. Por demás, también ha señalado la Casación civil que los principios de seguridad jurídica, confianza legítima y debido proceso, entre otros, sirven para materializar el principio constitucional de igualdad (Sentencia del 01 de agosto de 2014).

\section{PRINCIPIO DE SOLIDARIDAD}

Se trata aquí de solidaridad como pauta de comportamiento en determinadas situaciones (acerca de lo que puede entenderse por solidaridad en algunas de sus varias acepciones, véase Cortés, 2009b, p. 82). Desde una perspectiva constitucional, Correa Henao sostiene lo siguiente:

Tampoco se pierde de vista la actual importancia que comienza a adquirir el principio de solidaridad en la configuración constitucional [...] apenas se va consolidando y va trascendiendo de la dimensión ético filosófica para convertirse en imperativo frente a los poderes públicos y en deber, obligación, responsabilidad de los particulares, para ser reconocido, entre otras, bajo la forma de derechos fundamentales con garantías judiciales eficaces y de obligaciones y deberes exigibles (209, p. 111).

La solidaridad es un valor constitucional con una triple dimensión: es el fundamento de la organización política (Constitución Política, artículo 1); sirve de pauta de comportamiento conforme al que deben obrar las personas; sirve como un criterio de interpretación en el análisis de las acciones u omisiones de los particulares que vulneren o amenacen los derechos fundamentales (artículos 86 y 95-1; véase, además, Acción de tutela instaurada por Jaime Alberto Cantor, Carlos Sánchez y Lino Alonso con respecto al derecho al ambiente sano, a la calidad de vida y al derecho de petición). No obstante, resulta difícil indicar en qué medida el principio de solidaridad incida directamente en la autonomía privada de los particulares (véase Bianca, 2000, p. 33). Esto se debe, precisamente, a que el reconocimiento de la libertad del individuo se observa, hoy en día, en el marco de un ordenamiento que se inspira en el valor de la solidaridad social como valor de fondo del orden jurídico constitucional (p. 32). 
El principio de solidaridad no se agota en el solo deber constitucional, la Corte lo ha reconocido como un principio fundamental en toda su comprensión, por ello, «como principio [...] imprime ciertos parámetros de conducta social a los particulares, que pretenden racionalizar ciertos intercambios sociales» (Jurgen Huelsz... c. Juzgado 13 Civil de Circuito de Bogotá..., consideración 3.3.1; acerca de un deber de solidaridad y la exigencia para el juez de tutela de proteger derechos fundamentales, la Corte afirmó lo siguiente en la misma consideración: «el juez de tutela puede exigir el cumplimiento de un deber de solidaridad a un particular, cuando su incumplimiento afecte los derechos fundamentales de una persona que, por ausencia de regulación legal, carece de protección»). La solidaridad en el derecho privado tiene, a su vez, la función de coadyuvar en la tarea de mitigar los efectos dañosos que puede llegar a tener la vida en sociedad, por lo que solidaridad y reparación coinciden en cuanto a la finalidad que persiguen (véase Koteich Katib, 2012, p. 311). En el Estado social de Derecho, el principio de solidaridad cumple la función de corregir sistemáticamente algunos de los efectos nocivos que tienen las estructuras sociales y económicas sobre la convivencia política a largo plazo, por ello su indudable relevancia para la disciplina de las obligaciones - en ese sentido, afirma lo siguiente la Corte Constitucional: «Por supuesto, la solidaridad, como principio exigible a los particulares, no es un instrumento necesario para garantizar la convivencia política, independientemente del modelo de Estado. Se trata más bien de una construcción histórica, de una herramienta que acogió el Constituyente de 1991, como instrumento normativo consistente con su opción política por el Estado Social de Derecho» (Jurgen Huelsz... c. Juzgado 13 Civil de Circuito de Bogotá..., consideración 3.3.1; sobre los riesgos de la vida en sociedad y el derecho de la responsabilidad, véase Henao, 1998, p. 28). De ahí que el principio de solidaridad imponga, por ejemplo, a las entidades financieras un deber de consideración hacia los deudores del sistema financiero que han sido liberados después de un secuestro.

En desarrollo de sus actividades, estas entidades no pueden imponerles a los deudores que hayan sido secuestrados cargas que superen sus posibilidades de cumplir libre y responsablemente sus obligaciones financieras. Particularmente, en aquellas circunstancias en que la conducta de las entidades bancarias incida directamente sobre las posibilidades de readaptación a la actividad económica y social de estas personas (Jurgen Huelsz... c. Juzgado 13 Civil de Circuito de Bogotá..., consideración 3.3.4).

Se trata, pues, de la afectación de un derecho fundamental por incumplimiento del deber de solidaridad frente a personas en circunstancia de debilidad manifiesta. Dijo la Corte en la misma sentencia: 
Existen diversos mecanismos para establecer si el Estado o un particular están afectando un derecho fundamental. El más sencillo consiste en establecer si la conducta del Estado o de un particular desencadena una serie de consecuencias que afectan uno o más bienes jurídicos que hacen parte del ámbito protegido por un derecho fundamental. En este evento, el juez debe constatar, simplemente, si la acción del Estado o del particular determinó directamente la afectación del bien jurídico protegido. Sin embargo, constatar la violación de un derecho fundamental no siempre resulta tan sencillo. La afectación de los derechos fundamentales no siempre supone una relación causal inmediata y mecánica entre la conducta de un agente y la producción de una consecuencia nociva para los derechos fundamentales (consideración 3.2; en la doctrina véase Franco Victoria, 2011, pp. 235ss.).

Se deduce lógicamente que este deber de solidaridad, en rigor, no constituye propiamente un límite a la autonomía privada, sino que se funda más bien en la noción de libertad.

Pero una cosa es el principio de solidaridad y otra el llamado solidarismo contractual, aunque tengan una innegable relación. Se habla de solidarismo contractual y de cooperación entre las partes para el equilibrio del contrato. Este solidarismo está ligado en el ámbito contractual al interés socialmente relevante, socialmente útil y, por ende, meritorio de tutela por parte del ordenamiento jurídico. Pero también en materia de daños se debe señalar que la atención se desplazó del causante del daño hacia la víctima, y ello está ligado al principio de solidaridad, en especial cuando se afecta un interés de gran valor para la sociedad. Por ello, este principio se emplea en la actualidad como criterio de integración de la disciplina de la responsabilidad (Cortés, 2009b, p. 82).

Como bien señala Cortés, «sin duda la materia de las obligaciones no escapa a las ideologías imperantes: el enfrentamiento, o mejor, la tensión entre un liberalismo (individualista) que propende por el respeto de las voluntades, y un solidarismo que busca privilegiar el equilibrio de las partes de la relación, marca la pauta del debate actual» (2011, pp. 200ss.). Además, el autor explica cómo la doctrina del solidarismo en materia de obligaciones de contrato no tiene una aproximación puramente subjetiva y relativa del contrato, sino que la solidaridad es inherente a la noción misma de contrato, pues ella se pone de manifiesto en el sentimiento de confianza que nace al momento de su celebración, y que se traduce en el hecho de poner en manos del contratante el interés propio y a la vez hacerse cargo de su interés. Por medio de ella se logra no solo el fin buscado por las partes con la operación económica, sino también que la relación obligatoria se ajuste a las finalidades sociales que persigue el ordenamiento. 
Así pues, no es posible concebir la figura contractual sin que la autonomía privada empleada para hacer uso del tipo negocial no esté dirigida a un interés reconocido como socialmente útil, que no corresponda con la justicia social, con el principio social o la utilidad pública (Hinestrosa, 2015, pp. 125ss.). Esto es solidarismo contractual, que no es exactamente lo mismo que el principio de solidaridad. La función del instrumento contractual supone un contenido económico-social o práctico-social. En él caben la función social y ecológica, la responsabilidad social, la no discriminación, la producción de igualdad, la corrección y la honestidad, en fin, la solidaridad y la justicia en el contrato. El contrato no es autosuficiente, como señala Benítez Caorsi, no se basta a sí mismo, ya que solo es posible gracias a una reglamentación de origen social, que dé prevalencia a la protección del sujeto mediante instrumentos de justicia social que deben estar orientados como proyecto guiado hacia la libertad (véase Benítez Caorsi, 2013, p. 84).

\section{PRINCIPIO DE AUTONOMÍA PRIVADA}

En estrecha relación con la libertad —aunque no es esta la sede para afrontar dicha argumentación-, se encuentra el principio de autonomía privada, que se define en la doctrina civil como «el poder de los particulares para regular por sí mismos, de manera libre y vinculante, sus propios intereses; o más ampliamente, como el poder de un sujeto para decidir sobre su propia esfera jurídica» (Cortés, 2009a, p. 30). De inmediato se piensa que esta categoría es una expresión del principio de libertad y que, por otro lado, se refiere solamente a las obligaciones de contrato y no a las de daño. Las explicaciones sobre el negocio jurídico y la autonomía privada coinciden en ver detrás el principio y la dimensión de la libertad (véase Hinestrosa, 2015, pp. 297ss. y la nota 886, con cita de Galgano, Rescigno, Barcellona, Rodotà, Flour et al.). La autonomía privada es una categoría ante todo social y, por lo mismo, histórica (p. 185).

A esto se debe, precisamente, que el contrato tenga por virtud del ordenamiento una fuerza de ley, y de allí entonces que, legitimada la autonomía del particular, tenga este una autorresponsabilidad y unos límites para su ejercicio. En otras palabras, el reconocimiento legal de dicha autonomía pone en marcha una situación de responsabilidad (Cortés, 2009a, pp. 34ss.). Así, la libertad de contratación en nuestro tiempo se ha transformado - de libertad según las propias conveniencias y oportunidades - en la necesidad de observar un comportamiento jurídicamente relevante, es decir, de los viejos principios a las nuevas realidades (pp. 37ss.). En esta línea, es posible hablar de la función que ahora pasa a cumplir la autonomía privada (y obviamente la libertad negocial) de realización de los valores constitucionales (véase Gramunt

NOTAS SOBRE

ALGUNOS

PRINCIPIOS

GENERALES

DEL DERECHO:

UNA REFLEXIÓN

A PARTIR DE

PRINCIPIOS

GENERALES Y

SU INFLUENCIA

EN LAS

OBLIGACIONES EN

LA EXPERIENCIA

JURÍDICA

COLOMBIANA

NOTES ABOUT

SOME GENERAL

PRINCIPLES OF

LAW: A VIEW OF

SOME GENERAL

PRINCIPLES AND

THEIR INFLUENCE

ON THE LAW OF

OBLIGATIONS

IN COLOMBIAN

LEGAL

EXPERIENCE 
\& Florensa, 2017, p. 145 y nota 49, con cita de Messineo, Galgano, Alpa et al.).

No obstante, no podemos olvidar que en las relaciones de consumo se presenta una asimetría estructural. Por ello, para especial protección de la parte débil de la relación, se interviene limitando la autonomía privada a su favor en la medida en que las reglas de protección son inderogables e inmodificables (Cuffaro, 2008, p. 617). Sin embargo, no es el único caso de limitación; en general, el orden público y las buenas costumbres, y los derechos fundamentales son los grandes límites del ejercicio de la voluntad del individuo en uso de su poder de disponer de lo propio de acuerdo con el derecho en la forma de autonomía privada.

Autonomía privada significa posibilidad para los particulares de regular libremente las relaciones jurídicas con otras personas, de allí que el negocio jurídico sea el instrumento para realizar la autonomía privada (Hinestrosa, 2015, p. 117; Scognamiglio, 1971, p. 27). El negocio jurídico sirve de vehículo al poder de autodeterminación para disponer de lo propio, de los elementos integrantes del patrimonio (posición exterior de la persona), de sus cosas, de su fuerza de trabajo, de sus relaciones de familia, y de bienes de su personalidad. En última instancia, es un poder perteneciente al individuo de regular sus propios intereses, reconocido, pero no conferido por el derecho objetivo, pues su origen prístino se encuentra en la conciencia social (véase Hinestrosa, 2015, p. 117, nota 230; Trimarchi, 2011, p. 153; para aspectos relacionados con la autonomía privada y colectiva, Mantello, 2007).

La doctrina constitucional encontró terreno fértil en la amplia dogmática privatista sobre la autonomía privada, para señalar entonces que «[l]a autonomía de la voluntad privada y, como consecuencia de ella, la libertad contractual gozan entonces de garantía constitucional» (Acciones de tutela instauradas por Gilberto Gaviria Posada y Luis Enrique Villalobos Castaño contra entidades bancarias particulares, fundamento 8). Sin embargo, en múltiples providencias, la Corte ha señalado que aquellas libertades «están sometidas a condiciones y límites que le son impuestos, también constitucionalmente, por las exigencias propias del Estado social, el interés público y por el respeto de los derechos fundamentales de otras personas» (fundamento 8).

Entonces, evidentemente la autonomía de la voluntad privada goza de sustento constitucional, y dicho postulado se deriva, en la jurisprudencia, de la aplicación de varios derechos constitucionales concurrentes: el derecho al reconocimiento de la personalidad jurídica (Constitución Política, artículo 14), el derecho a la propiedad privada (artículo 58), la libertad de asociación (artículos 38 y 39), la libertad económica, la libre iniciativa privada y la libertad de empresa (artículos 333 y 334). Es el conjunto de estos derechos constitucionales el que confiere a los 
asociados la potestad de crear, modificar y extinguir relaciones jurídicas desde un punto de vista constitucional y para todo el ordenamiento.

Sin embargo, se reconoce que en el derecho positivo colombiano se ha construido el postulado de la autonomía de la voluntad privada a partir del contenido normativo previsto en el artículo 1602 del Código Civil, conforme al cual, "Todo contrato legalmente celebrado es una ley para los contratantes...» (véase la sentencia de la Corte Constitucional para el caso Cooperativa Multiactiva de Empleados de Distribuidoras de Drogas (Copservir Ltda) c. Banco de Bogotá, Bancolombia, Interbanco, Banco de Occidente, Bancafé, Granahorrar y Banco Agrario de Colombia). En la recién citada sentencia, la Corte señaló que

en un principio se consideraba que la autonomía privada constituía una emanación de la voluntad general — como fuente absoluta e inagotable de todo derecho-, erigiéndose, entonces, en un poder ilimitado y omnímodo de autodeterminación normativa (concepción racionalista). Sin embargo, con el surgimiento de los postulados sociales del Estado de Derecho, se relativizó su alcance en favor de la salvaguarda y protección del bien común, el principio de solidaridad y los derechos de los terceros (concepción moderna). Luego, la autonomía de la voluntad privada se concibe no solo como un simple poder subjetivo de autorregulación de los intereses privados, sino como el medio efectivo para realizar los fines correctores del Estado social, a través del mejoramiento de la dinámica propia del mercado (fundamento $3.5,15$ ).

No obstante la regla pacta sunt servanda, vale la pena preguntarse cómo incide la buena fe sobre el contenido de la autonomía privada (véase Castronovo \& Mazzamuto, 2007, pp. 310ss., en especial sobre la relación entre la ley y el acto de autonomía privada), por lo cual la regla de la fuerza vinculante se encuentra siempre en discusión.

La autonomía privada en su prisma constitucional deviene en un derecho íntimamente ligado y vinculado a la dignidad de la persona humana, en la medida en que sirve como instrumento principal e idóneo para la satisfacción de las necesidades básicas mediante el poder que le otorga el ordenamiento positivo para regular sus propios intereses (Cooperativa Multiactiva de Empleados de Distribuidoras de Drogas (Copservir Ltda) c. Banco de Bogotá...). De ahí que se hable de un cierto grado razonable de autorregulación y autorresponsabilidad de los asociados, «a través del reconocimiento de un núcleo esencial de libertad contractual, destinado a suplir la imposibilidad física, técnica y jurídica del Estado para prever ex-ante todas las necesidades de las personas» (fundamento 3.5, 14).

Si bien no hay una norma general que consagre la autonomía privada en la legislación civil y comercial, sí encontramos todo un conjunto de normas que expresan claramente su aplicación en tales materias.

NOTAS SOBRE

ALGUNOS

PRINCIPIOS

GENERALES

DEL DERECHO:

UNA REFLEXIÓN

A PARTIR DE

PRINCIPIOS

GENERALES Y

SU INFLUENCIA

EN LAS

OBLIGACIONES EN

LA EXPERIENCIA

JURÍDICA

COLOMBIANA

NOTES ABOUT

SOME GENERAL

PRINCIPLES OF

LAW: A VIEW OF

SOME GENERAL

PRINCIPLES AND

THEIR INFLUENCE

ON THE LAW OF

OBLIGATIONS

IN COLOMBIAN

LEGAL

EXPERIENCE 
En especial en relación con las obligaciones de contrato, la jurisprudencia y la doctrina le reconocen el carácter de principio en virtud del cual es posible crear nuevos tipos contractuales y realizar pactos de exclusividad que se consideran válidos en principio, pues se proscribe solo el que tiene el efecto real de restringir el acceso de los competidores en el mercado (Demanda de inconstitucionalidad contra el artículo 19 de la Ley 256 de 1996 «por la cual se dictan normas sobre competencia desleal»; véase, además, Autores varios, 2012, pp. 212ss.).

Se plantea la cuestión de si la autonomía privada se pueda extender al campo de las obligaciones provenientes del daño. No es esta la sede para afrontar esa discusión, sin embargo, de forma preliminar, me atrevo a pensar que no sería posible en la medida en que la autonomía privada supone darse derecho en el sentido de autoprogramar, de autorregular. Esto entraría en tensión con el ilícito civil que supone la contrariedad al derecho (damnum iniuria datum). La autonomía privada es una cuestión de la obligación de fuente negocial, y, antes, es un reconocimiento a la libertad del sujeto consagrada en la Constitución, libertad para regular lo propio y darle efectos de acuerdo con el ordenamiento, no para transgredir normas o los fines del derecho.

\section{VII.PRINCIPIO DE BUENA FE}

La buena fe se erige como principio basilar de toda disciplina jurídica. Ella tiene un significado profundo y amplio (tal y como recuerda Cicerón que decía Quinto Mucio Escévola: vide amplius, véase Neme Villarreal, 2010, p. 237), con su plurisecular historia. Ella es el resultado de una paulatina sedimentación de soluciones fundadas en tal principio cuyo desarrollo ha girado en torno a la materia contractual (Facco, 2017, p. 29). Histórico, sistemático y primordial elemento constitutivo del derecho, el principio general de buena fe irradia todo el sistema jurídico de tradición romanista y ha sido recogido en nuestros códigos y constituciones; ampliamente difundido en la doctrina y la jurisprudencia. En materia de obligaciones, este principio encuentra su mayor desarrollo y reconocimiento; la bibliografía pierde confines. No es nuestra pretensión aquí referir todo ese material, sería superfluo, se pretende - tal y como se anunció en el inicio- contribuir a un elenco de los principios vigentes y los nuevos que se suman a los tradicionales. Pese al origen ex fide bona de este principio en el derecho civil, la buena fe está consagrada como precepto constitucional en el artículo 83 de la Constitución Política de Colombia: «Las actuaciones de los particulares y de las autoridades públicas deberán ceñirse a los postulados de la buena fe, la cual se presumirá en todas las gestiones que aquellos adelanten ante estas».

La fe, sin más, antes de que se le agregue el adjetivo calificativo de buena, se observa como virtud y comportamiento honesto, diligente, leal. El 
calificativo se agregó especialmente en relación con la posesión, y de allí que no deba confundirse con la buena fe negocial (véase el salvamento de voto de Hinestrosa a la Sentencia del 07 de mayo de 1968, pp. 117ss.; Hinestrosa, 2015, p. 387). La buena fe, como principio fundamental del sistema jurídico y basilar del derecho contractual, evolucionó en la modernidad a partir de la noción que de ella recogió el código civil y ha sido uno de los principios más enriquecidos por la legislación, la doctrina y la jurisprudencia (Giraldo Bustamante, 2014, pp. 142ss.).

Como principio fundante del sistema, la buena fe implica una pluralidad de relaciones jurídicas y su aplicación se ajusta a la especificidad de las relaciones y sus connotaciones en la variedad de situaciones particulares que deben ser reglamentadas en la vida cotidiana entre ciudadanos, y entre ciudadanos y el Estado. Este principio - junto con la dignidad humana, la libertad, y la igualdad — puede considerarse no solo principio basilar de sistema, sino también «principio de principios» (se recuerda desde el punto de vista del sistema que el derecho en sí mismo encierra lo que es más justo y produce igualdad: ius est ars boni et aequi). En efecto, la fisonomía de la buena fe se expresa en un «derecho viviente» que trasciende la regla escrita (Santamaria, 2012, pp. 6ss.). Así, pues, toda relación jurídica debe ajustarse al postulado de corrección, honestidad, probidad, colaboración, el actuar pundonoroso, en fin, de buena fe en las relaciones negociales y en todo tipo de relaciones y de actuaciones jurídicas y sociales. En este sentido, la buena fe tempera la libertad contractual en particular (Tisseyre, 2012, pp. 46ss.). Es una regla de comportamiento a la que se debe ajustar y cuya impronta debe llevar toda actividad jurídica en lo público y en lo privado. De manera que la buena fe supone, entre otras, una dimensión ética de la autonomía privada (véase Falco, 2010, pp. 12ss.).

El artículo 1603 del Código Civil colombiano prescribe lo atinente a la buena fe objetiva, en la ejecución y en la integración del contenido del contrato, al señalar que «los contratos deben ejecutarse de buena fe», seguido de la expresión «y por consiguiente», deben cumplirse no solo de acuerdo con lo expresamente pactado, sino también de acuerdo con todos aquellos deberes que emanan «precisamente de la naturaleza de la obligación, o que por la ley pertenecen a ella» (véase Autores varios, 2012, p. 207). A su vez, el Código de Comercio, en el artículo 871, consagra la buena fe en la integración y ejecución de los contratos, vinculándolos con la costumbre y la equidad natural. En el artículo 863 , el mismo Código comercial extiende el alcance de la buena fe al periodo precontractual.

En cuanto a la buena fe subjetiva, el Código Civil, en el artículo 768, identifica la buena fe con una «conciencia» que se presume. También se refiere el Código a la buena fe subjetiva en materia de adquisición

NOTAS SOBRE

ALGUNOS

PRINCIPIOS

GENERALES

DEL DERECHO:

UNA REFLEXIÓN

A PARTIR DE

PRINCIPIOS

GENERALES Y

SU INFLUENCIA

EN LAS

OBLIGACIONES EN

LA EXPERIENCIA

JURÍDICA

colombiana

NOTES ABOUT

SOME GENERAL

PRINCIPLES OF

LAW: A VIEW OF

SOME GENERAL

PRINCIPLES AND

THEIR INFLUENCE

ON THE LAW OF

OBLIGATIONS

IN COLOMBIAN

LEGAL

EXPERIENCE 
de bienes muebles en establecimientos comerciales, en la resolución de contrato cuya condición resolutoria no ha sido publicitada, en los negocios simulados frente a terceros, en los pagos realizados a un falso acreedor, en los negocios celebrados con el heredero putativo a quien por decreto judicial se le haya otorgado la posesión efectiva de bienes de la herencia. El Código de Comercio hace referencia a la buena fe subjetiva en el artículo 834 en relación con el contrato de mandato, y en los casos de nulidad de contratos frente a terceros de buena fe acorde con el artículo 105 del mismo código. No es necesario destacara que la jurisprudencia y doctrina reconocen a la buena fe el carácter de principio general del derecho (véase las siguientes sentencias: Sentencia del 20 de mayo de 1936; Sentencia del 07 de octubre de 2009; Acción de tutela instaurada por Danilo Molina con respecto al derecho a la salud, a la libertad de locomoción y a la libertad de residencia; Acción de tutela instaurada por Neyla del Carmen Navas Contreras en representación de su hermano Juan Manuel Contreras contra el Instituto de Seguro Social; Demanda de inconstitucionalidad contra los artículos 252 (total) y 373 (parcial) del Código de Comercio; para una referencia a la doctrina atendible, véase Autores varios, 2012, pp. 212ss.).

Como señala Ordoqui, la buena fe no es un concepto inventado por la doctrina, sino que es una valoración de conductas tomada de la realidad social intersubjetiva que está en la naturaleza de la persona, y en su noción objetiva se refiere a una ética normativa (Ordoqui, 2012, p. 102). Como bien señala la profesora Martha Neme Villarreal, «la buena fe no solo integra el contenido del contrato mediante la adición del contenido contractual, sino que también lo hace mediante la exclusión o modificación de las cláusulas contenidas en el acuerdo, como en el caso de la aplicación de la cláusula rebus sic stantibus o teoría de la imprevisión, la lesión enorme, la anulación de cláusulas abusivas» etcétera (2006, p. 90).

En relación con los últimos avances en la armonización del derecho latinoamericano, se presenta el artículo 7 de los PLDC, que introduce la buena fe contractual. La norma dispone que las partes deben comportarse conforme a las exigencias de la buena fe. Las limitaciones convencionales contrarias a la buena fe no producen efecto alguno. Por su parte, el GADAL propone el artículo 7 del Código Marco de Obligaciones, e introduce el principio de buena fe, su ámbito de aplicación y su carácter imperativo. La norma de armonización del GADAL dispone que el principio de buena fe rige el vínculo obligacional en su surgimiento, cumplimiento y extinción, y que, en consecuencia, el acreedor y deudor deberán comportarse de modo que preserven la integridad de las ventajas legítimas del vínculo obligacional. En cuanto a la ineficacia de los pactos contrarios a la buena fe o que la excluyan, se establece que la aplicación del principio de buena fe no podrá excluirse. 
Así, también se establecen las funciones integradora e interpretadora de la buena fe en el artículo 8, que dispone que el contenido y alcance del vínculo obligacional deberán integrarse e interpretarse de conformidad con el principio de buena fe, atendiendo a su fuente, naturaleza y finalidad. Por último, el artículo 10 del mismo Código Marco establece la prohibición de ir contra los actos propios. El acreedor y el deudor deben observar la exigencia de coherencia que impone la buena fe y, en consecuencia, no podrán actuar en contradicción con conductas precedentes que hayan generado una confianza legítima en los demás sujetos del vínculo obligacional.

Una última y también breve referencia a instrumentos de armonización europeos. En los Principios UNIDROIT se establece que las partes deberán obrar con buena fe y lealtad negocial, y se asegura el carácter contundente del principio de buena fe (artículo 1.7; sobre los citados Principios y sobre los problemas y retos de la armonización en general, véase Cartwright, 2018, pp. 3ss.; Ferrante, 2016, pp. 116ss.). También asume la buena fe, en estos Principios, la función de criterio normativo de integración (artículo 4.8). La buena fe no se encuentra normada con carácter de pauta hermenéutica en los Principios, pero también con fundamento en ella se permite la intervención en el contrato como forma de control de los abusos de uno de los contratantes en los casos de marcado desequilibrio en la figura de la excesiva desproporción (artículo 3.10). En el Marco Común de Referencia Europeo (su acrónimo en inglés DCFR), la buena fe se presenta sistemáticamente dentro del capítulo de seguridad contractual (I. 1:103), absorbida en este principio. Se la define como una estándar de conducta caracterizado por la honestidad, franqueza y consideración por los intereses de la otra parte, esto es, buena fe objetiva o regla de comportamiento inspirada en la exigencia de lealtad (Facco, 2017). También las negociaciones previas deben conducirse de acuerdo con la buena fe y no pueden ser rotas en transgresión del principio, so pena de indemnizar los perjuicios causados (DCFR, II. 3:301 § 2). Otras referencias a la buena fe en el DCFR, las encontramos en materia de interpretación del contrato (II. 8:101), integración del contrato (II. 9:101), cláusulas abusivas (II. 9:404). Finalmente, la propuesta de una Normativa Común de Compraventa Europea (CESL por sus siglas en inglés) establece en el artículo 2 la buena fe contractual, «cada parte tendrá el deber de actuar conforme a las exigencias de la buena fe contractual», en línea con los demás proyectos de armonización. No obstante, en la enmienda 82 al artículo 2.2, el Parlamento Europeo pareciera haberle dado un viraje a la CESL, amputando la eficacia normativa de la buena fe. El artículo 2.2 establece que el incumplimiento del deber de buena fe podrá impedir a la parte incumplidora el ejercicio o la invocación de los derechos, acciones o medios de defensa que, en otro caso, tendría. La enmienda agregó

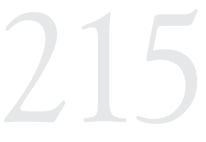

NOTAS SOBRE

ALGUNOS

PRINCIPIOS

GENERALES

DEL DERECHO:

UNA REFLEXIÓN

A PARTIR DE

PRINCIPIOS

GENERALES Y

SU INFLUENCIA

EN LAS

OBLIGACIONES EN

LA EXPERIENCIA

JURÍDICA

COLOMBIANA

NOTES ABOUT

SOME GENERAL

PRINCIPLES OF

LAW: A VIEW OF

SOME GENERAL

PRINCIPLES AND

THEIR INFLUENCE

ON THE LAW OF

OBLIGATIONS

IN COLOMBIAN

LEGAL

EXPERIENCE 
«pero no dará directamente lugar a acciones por incumplimiento de una obligación» (P7_TA(2014)0159). El sujeto afectado tendrá que conformarse con esgrimir la eficacia negativa del principio y estaría solamente legitimado para oponerse a la acción en su contra (Facco, 2017, p. 367).

En sustancia, para cerrar, la buena fe implica una apreciación dinámica de la relación obligacional acorde con las exigencias de la realidad económica actual. En efecto, ella permite individualizar los deberes colaterales de conducta que los contratantes han de observar, los cuales pueden variar según la función que desempeñe el contrato en cada caso en concreto (Facco, 2017, p. 391 y nota 13).

\section{PRINCIPIO DE EQUIDAD}

Otro principio fundamental del sistema es la equidad, también respecto de ella, como de los demás principios aquí enunciados, se han escrito volúmenes inacabables, mucho podría decirse también sobre este principio. Este principio es basilar en el derecho por definición, siendo así el derecho un sistema de lo justo y de lo que produce más igualdad (aequare) (Facco, 2017, p. 121). Desde el aequare libertatem hasta la reductio ad aequitatem en la actualidad, este principio es de enorme alcance y relevancia. Busca lo que es productor de igualdad, lo que es más equitativo. Hablamos de equidad en especial en las obligaciones de contrato. La equidad es un principio que rige tanto la formación como el cumplimiento de las obligaciones de fuente contractual. Se le reconoce función integradora del contenido de la relación jurídica obligatoria y en la determinación de su objeto.

Este principio encuentra aplicación en el ordenamiento jurídico en la medida en que converge en su actuación con el principio general de buena fe. Ambos actúan, por ejemplo, en las obligaciones de contrato mediante los remedios contra el aprovechamiento de los estados de debilidad de los contratantes en el iter de la formación de las obligaciones de contrato (véase Morales Hervias, 2010, pp. 211ss., 2016). Asimismo, se consagran remedios para mantener el equilibrio de las prestaciones durante el cumplimiento de tales obligaciones, cuando, sobre la base de la equidad, se conceden facultades al juez para el reajuste de las prestaciones.

La moderación de los contratos en el sentido de evitar indebidos aprovechamientos de la debilidad ajena, o la misma distribución equitativa de los riesgos sobrevinientes, son expresiones no solo de una idea de moderación, sino también de una búsqueda de aquello que es más justo y que produce igualdad. Era el reclamo a un principio difuso entre los comentadores medievales, y consolidado por el derecho 
común, según el cual «contractus quia habent tractum successivum et dependentia de futuro, rebus sic stantibus intelligutur». Se trata de una equidad quidem est amirabile quoddam temperamentum, la perfecta ratione que omnia moderatur; y, como hemos señalado en otro lugar, una reductio basada en la aequalitas que en omnes contractus servanda para corregir toda extrema iniquidad. La justificación interpretativa de la equidad $-\mathrm{y}$ los insistentes llamados a ella — no debe entenderse aislada, se trata del rasgo esencial del sistema del bono et aequo. Así, las palabras del jurista medieval Francesco Mantica lo explican para todos los tiempos: Bono etiam aequo descendit, ut contractus debeat intelligi rebus in eodem statu manentibus (citado en Chamie, 2012, p. 229).

El fundamento de este principio se observa, por ejemplo, en instituciones como la lesión enorme, la reducción de la cláusula penal enorme, la reducción de los intereses desproporcionados, la prohibición al aprovechamiento de los estados de necesidad, la prohibición a cláusulas abusivas, entre otros. En la obligación de contrato, se trata de una protección en atención a los criterios de equidad (humanum est). Se protege la especial situación del contratante lesionado (su estado de necesidad o de peligro: vis generalis), ya que su voluntad, si bien no disminuida del todo, se encuentra de todas maneras presionada por una situación que está fuera de su poder de control. En estrecha relación con esto, se prohíbe todo abuso que de esa situación pueda realizar la contraparte (abuso del derecho, dolo, aprovechamiento) para obtener una ventaja injusta o inicua (enriquecimiento sin causa, o con una causa ilícita basada en la exploitation), generando una notoria desproporción entre las prestaciones (desequilibrio contractual, falta de equivalencia). Se rompe la equivalencia en la posición jurídica de las partes, de allí que la equidad correctiva busque producir más igualdad (aequare).

Se califica hoy como «indebido aprovechamiento» la conducta de quien toma ventaja injusta en un contrato celebrado bajo la influencia de un estado de debilidad de la contraparte, pues no de otra forma el contrato estaría desequilibrado, a menos que la desproporción se deba a un error en el precio. No obstante, dicha conducta, si bien no entra en la hipótesis de dolo prevista en la ley, le está bastante cercana al ser contraria a la bona fides y portadora de una idea de macchinatio (pues hay un lucrari cum damno alterius). Esto, quizá, fue lo que llevó a los glosadores y a toda la ciencia jurídica secular a explicar la lesión a la luz de un dolus re ipsa, un principio de engaño, un dolo evidente en la cosa misma, es decir, por el hecho mismo (la desproporción). Un dolo que no es dolo fue el afortunado oxímoron de los doctores medievales, que identificó la lesión con el dolus y que luego, dada la creación de la categoría de los vicios de la voluntad, hubo de ser incluida como autónoma dentro de estos (véase Chamie, 2012). 
El aprovechamiento injusto naturalmente es un actuar contrario a la buena fe en la medida en que es una forma de dolo. Pero actúa la equidad para buscar restablecer el equilibrio quebrado, restaurar la equivalencia (aequalitas), aplicar un remedio equitativo que busque lo que es más productor de igualdad. Se debe partir de esta constatación: si es cierto que la situación de libertad aminorada en la que se encuentra el contratante lesionado no fue provocada por la contraparte, es cierto también que esta, con la propia conducta, ayuda a determinar las consecuencias de dicha situación causando el desequilibrio del contrato. El «aprovechamiento» apunta entonces hacia una voluntad ya disminuida, permitiéndole al contratante doloso incidir, respecto de la patología de las negociaciones, de forma anómala en la determinación del contenido contractual. Si bien puede creerse que deba prevalecer la causalidad, no puede afirmarse que la conducta del contratante que se aprovecha sea la causa exclusiva de la lesión, en cuanto el daño proviene propiamente del contrato desequilibrado.

En todoesto, cabe preguntarse hasta qué puntopuede el aprovechamiento calificarse como un hecho ilícito y, asimismo, hasta qué punto puede considerarse la rescisión como sanción civil del aprovechamiento, lo que de todos modos entra en crisis a la luz de la posibilidad de reductio ad aequitatem, carácter prístino dentro de la estructura de la figura, su base radicada en la corrección igualadora de la equidad (Chamie, La corrección del contrato).

Lo mismo puede afirmarse en caso de ruptura funcional del equilibrio del contrato, de una difficultas económica relevante para los efectos del cumplimiento, una hipótesis, pues, de «inexigibilidad de la obligación» por disconformidad de la expectativa y el interés de una de las partes. También en este caso se rompe la equivalencia, pero con otros supuestos causales. La equidad interviene para de nuevo restablecer el equilibrio de ser posible, buscar lo más productivo de igualdad frente a la nueva circunstancia. Este es el problema contenido en la cláusula rebus sic stantibus, el problema de la compatibilidad entre el contrato y la realidad,

pero es también el problema de la vis ciu resisti non potest (Servio en D. 19, 2, 15, 2), el problema de la reductio ad aequitatem, que hoy encuentra diversos planteamientos (Geschäftsgrundlage, eccessiva onerosità, imprevisión, force majeure, hardship, bouleversement, entre otras) pero en el fondo todos tienen que ver con el mismo principio: la moderación de los contratos, su reductio-remissio equitativa en caso de desequilibrio, su revisión conforme a buena fe y equidad (Chamie, 2012, p. 230, 2013, capítulo I y passim).

La equidad está presente también en la reparación integral del daño en la determinación de la cuantía de la indemnización, en particular 
en relación con los estándares mínimos del daño en el caso del lucro cesante, pero también en caso de cuantificación del pretium doloris (véase, solo para una referencia puntual, Hinestrosa, 1983, p. 680; Henao, 1998, pp. 56, 40-41).

Hay un clamor constante por la equidad, piénsese en el llamado que hace el Codice civile italiano a este principio, al referirse a «condiciones inicuas» (artículo 1447), «compensación equitativa» (artículo1447), «modificación del contrato suficiente para conducirlo a la equidad» (artículo 1450). Recuerda aquella interpretación que del «humanum est» se hizo ya en el sistema medieval en términos de aequitas (empero, la equidad medieval no es la misma aequitas romana ni la misma del código italiano); la misma equidad de la que hablaba Pothier $(1761, \S$ IV, 33) y que Thomasius (1706, Diss. LXXII de aequitate cerebrina legis II Cod. de rescindenda venditione eiusque usu pratico, 62ss.) calificó de «cerebrina». Se trata de un concepto que forma parte del derecho por definición como ars boni et aequi y que justifica la intervención en lo acordado en el programa contractual, la intromisión para el restablecimiento del equilibrio del contrato, la reciprocidad, es decir, la equivalencia de las prestaciones.

La jurisprudencia ha señalado con precisión lo siguiente al respecto:

De acuerdo con el principio de equidad, cuando el juez está en la tarea de aplicar la norma legal al caso concreto debe tener en cuenta las circunstancias propias del mismo, de manera que la voluntad del legislador se adecue a los distintos matices que se presentan en la vida real. La tarea del legislador y la del juez son complementarias. El juez está llamado a afinar la aplicación de la norma legal a la situación bajo examen, con el objeto de lograr que el espíritu de la ley, que el propósito del legislador, no se desvirtúe en el momento de la aplicación, por causa de las particularidades propias de cada caso. Lo anterior no implica que el juez desatienda la norma legal, se aparte de la voluntad del legislador, sino que la module al caso concreto, evitando inequidades manifiestas o despropósitos, resultados que en todo caso también habría impedido el legislador si los hubiera podido prever. Es decir, de lo que se trata es de poner en vigencia el principio de colaboración entre las distintas ramas del poder público, lo cual implica que el juez colabore en el desarrollo de la norma dictada por el legislador, al adaptarla al caso concreto (Acción de tutela instaurada por Ana Rosa Serna con respecto a la responsabilidad constitucional de las autoridades municipales por los riegos a la vida y a la integridad personal que causan con ocasión de la realización de obras públicas y a la equidad en la aplicación concreta del derecho).

Aquí se trata es de armonizar no solo los instrumentos más relevantes para la defensa de la equidad en los intercambios, tanto en el momento

NOTAS SOBRE

ALGUNOS

PRINCIPIOS

GENERALES

DEL DERECHO:

UNA REFLEXIÓN

A PARTIR DE

PRINCIPIOS

GENERALES Y

SU INFLUENCIA

EN LAS

OBLIGACIONES EN

LA EXPERIENCIA

JURÍDICA

COLOMBIANA

NOTES ABOUT

SOME GENERAL

PRINCIPLES OF

LAW: A VIEW OF

SOME GENERAL

PRINCIPLES AND

THEIR INFLUENCE

ON THE LAW OF

OBLIGATIONS

IN COLOMBIAN

LEGAL

EXPERIENCE 
genético de las obligaciones de contrato, como en el momento dinámico de su ejecución. Se debe armonizar el valor de la equidad en materia de reparación integral del daño.

El principio de equidad tiene aplicación legal en relación con la tasación del monto de los perjuicios en cualquier proceso ante la Administración de Justicia, de conformidad con el artículo 16 de la ley 446 de 1998: «Dentro de cualquier proceso que se surta ante la Administración de Justicia, la valoración de daños irrogados a las personas y a las cosas, atenderá los principios de reparación integral y equidad y observará los criterios técnicos actuariales» (véase, por ejemplo, Amparo de Jesús Ramírez Suárez c. Hospital San Vicente de Paul de Lorica y otro; en particular, sobre la vigencia del citado artículo 16, véase las siguientes sentencias: Demanda de inconstitucionalidad contra el artículo 38 numeral 1 del Código de Procedimiento Civil; Demanda de inconstitucionalidad contra el artículo 205 del decreto 1355 de 1970 «Por el cual se dictan normas sobre policía»; Sentencia del 01 de abril de 2003; sobre el punto en la doctrina, véase, por ejemplo, Gamboa Morales, 2003, pp. 25ss.; Tamayo Jaramillo, 2007, pp. 347ss.).

Elementos adicionales para la reflexión se aportan en lo contenciosoadministrativo, donde el principio de equidad se ha tenido en cuenta para la flexibilidad en la apreciación y valoración de los medios probatorios frente a graves violaciones de derechos humanos e infracciones al derecho internacional humanitario, en relación con daños inmateriales (véase el fallo del Consejo de Estado en el caso Ana Rita Alarcón vda. de Gutiérrez y otros c. Municipio de Pereira). El mismo Consejo de Estado ha aplicado el principio de equidad en la reparación del daño a la salud (véase Gonzalo Cuellar Penagos y otros c. Ministerio de Defensa - Ejército Nacional).

El principio de equidad irradia a su vez en materia procesal los fallos en equidad y la jurisdicción de los jueces de paz, de acuerdo con el artículo 2 de la ley 497 de 1999: «Las decisiones que profieran los jueces de paz deberán ser en equidad, conforme a los criterios de justicia propios de la comunidad». La equidad se cita también para regular distintos aspectos de la Constitución Política (artículos 20, 95.9, 107, 116, 150.16, 226, 227, 230, 247, 267, 356 y 363), desde la cláusula general de Estado social de Derecho, hasta lo que tiene que ver con la distribución de la riqueza económica del país y la explotación de los recursos naturales. Llama la atención en Colombia que la ley 1480 de 2011 (Estatuto del Consumidor) no menciona la equidad en un tema sensible con la disciplina del derecho del consumidor. Sin embargo, incluye normas sobre principio de buena fe y otros principios como dignidad humana, seguridad y salud, que complementan ese derecho de protección. 
En relación con los últimos avances en la armonización del derecho de las obligaciones en Latinoamérica, el GADAL propone el artículo 11 del Código Marco de Obligaciones, con la rúbrica que alude al principio de equidad. El texto reza así: «La interpretación, determinación del contenido y exigibilidad de las obligaciones estarán guiadas por el principio de equidad, en armonía con los principios que inspiran este código».

\section{PRINCIPIO DE PROPORCIONALIDAD}

La prevalencia de los derechos fundamentales es una característica de nuestro tiempo. Sin entrar en la discusión sobre la llamada constitucionalización, lo cierto es que el cuestionamiento sobre la pertinencia de ampliar el catálogo de derechos y la supervisión de su correcta puesta en práctica exige el uso de técnicas interpretativas como la de la proporcionalidad (Carbonell, 2007, p. 10). La proporcionalidad es un principio general reconocido como tal no solo en el derecho comunitario europeo (Bernal Pulido, 2009, pp. 286ss.). En este sentido conviene cuestionarse sobre si la proporcionalidad sea o no un principio general o, más bien, una técnica interpretativa o un criterio de decisión, y si su función no la cumpla ya el principio de equidad o el de igualdad.

Este principio ha sido desarrollado en Alemania y aplicado por los diferentes tribunales constitucionales tanto europeos como latinoamericanos (Insignares-Cera \& Molinares-Hassan, 2012). Trata amplios temas, desde la limitación a la circulación de bienes, hasta la protección ambiental en los conflictos por espacio público — sin embargo, no ha faltado la opinión según la cual, a causa del principio de proporcionalidad, se ha formado un «culto académico a los derechos fundamentales» que ha desembocado en una concepción extremadamente individualista de los derechos y en un simultáneo desprecio hacia las leyes democráticas que persiguen la protección de intereses sociales (véase Webber, 2010, p. 180; Bernal Pulido, 2014, p. 33) - «Este principio cumple una función interpretativa y de alcance del contenido de un derecho fundamental, lo cual permite garantizar la supremacía de las normas relativas a derechos fundamentales frente a cualquier tipo de acto o providencia; así las cosas, el fin último es buscar la armonía entre sí de los derechos, principios y bienes constitucionales» (Bernal Pulido, 2014, p. 99, con cita de Sánchez Gil, El principio de proporcionalidad, 2007).

La jurisprudencia constitucional en Colombia ha dicho lo siguiente:

La teoría jurídica alemana, partiendo de la jurisprudencia del Tribunal Constitucional Federal, ha mostrado cómo el concepto de razonabilidad puede ser aplicado satisfactoriamente solo si se concreta en otro más

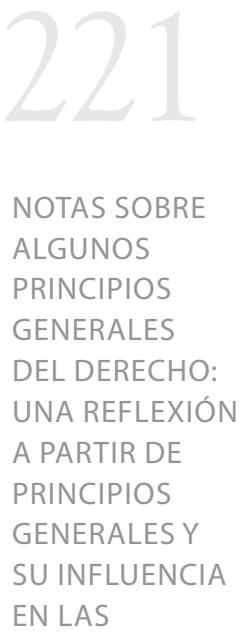

OBLIGACIONESEN

LA EXPERIENCIA

JURÍDICA

COLOMBIANA

NOTES ABOUT

SOME GENERAL

PRINCIPLES OF

LAW: A VIEW OF

SOME GENERAL

PRINCIPLES AND

THEIR INFLUENCE

ON THE LAW OF

OBLIGATIONS

IN COLOMBIAN

LEGAL

EXPERIENCE 
específico, el de proporcionalidad. El concepto de proporcionalidad sirve como punto de apoyo de la ponderación entre principios constitucionales: cuando dos principios entran en colisión, porque la aplicación de uno implica la reducción del campo de aplicación de otro, corresponde al juez constitucional determinar si esa reducción es proporcionada, a la luz de la importancia del principio afectado.

El concepto de proporcionalidad comprende tres aspectos de un procedimiento interpretativo: la adecuación de los medios escogidos para la consecución del fin perseguido, la necesidad de la utilización de esos medios para el logro del fin (esto es, que no exista otro medio que pueda conducir al fin y que sacrifique en menor medida los principios constitucionales afectados por el uso de esos medios), y la proporcionalidad en sentido estricto entre medios y fin, es decir, que el principio satisfecho por el logro de este fin no sacrifique principios constitucionalmente más importantes (Demanda de inconstitucionalidad contra el artículo 40, literal b, de la Ley 48 de 1993, consideración 6.3.3).

«Este principio favorece la interpretación en la medida en que, como señala Prieto Sanchís, no se constituye en una fórmula estática o "infalible" que pueda equipararse a los criterios de resolución de antinomias, sino que permite que las normas constitucionales se revisen a la luz de la necesidad y justificación de la tutela de otros derechos o principios en pugna» (Insignares-Cera \& Molinares-Hassan, 2012, p. 99).

En la medida en que se piense que no existen derechos absolutos, sino que el derecho se enfrenta a la posibilidad de ser limitado, la proporcionalidad se hace más relevante. Así, la cuestión es saber de qué manera y con cuáles requisitos se puede limitar los derechos, y, en particular, en el derecho de las obligaciones. Por su parte, la proporcionalidad se observa como técnica de interpretación que tiene como objeto tutelar los derechos fundamentales de la mejor manera, expandiendo tanto como sea posible su ámbito de protección, pero al mismo tiempo procurando que todos los derechos sean compatibles entre ellos en la medida en que sea posible (Carbonell, 2007, p. 10). Desde esta perspectiva, puede también afirmarse que la proporcionalidad constituye el «límite de los límites» a los derechos fundamentales y, en esa medida, podría hablarse de principio general de manifestación de la justicia, o de la razonabilidad.

Como tal, la proporcionalidad cumple una función interpretativa y vale como expresión del Estado social de Derecho. En el derecho de las obligaciones, la proporcionalidad inspira la idea de la calidad de la relación que debe mediar entre las posibilidades del acreedor y las necesidades del deudor (por ejemple, considérese la obligación alimentaria o la lesión contractual por la ruptura en la equivalencia de 
las prestaciones, o en materia fiscal, o electoral; véase Carbonell, 2007, p. 315).

En la jurisprudencia constitucional colombiana, el principio de proporcionalidad ha sido tratado ampliamente ${ }^{1}$, pero, en la jurisprudencia de la casación civil colombiana, no parece que haya un rol asignado con claridad al principio de proporcionalidad. Las menciones al mismo son ocasionales y sin una línea identificable con exactitud en pocas decisiones. En un primer momento, apenas posterior a la vigencia de la Constitución política de 1991, la jurisprudencia de la Casación civil solo hacía referencia a la proporcionalidad como «criterio» general sin una función específica que permita una consideración como principio general. Por ejemplo, en el caso concreto de la proporcionalidad en el pago de la indemnización al asegurado a la luz del artículo 1091 del Código de Comercio (Sentencia del 23 de setiembre de 1993). Posteriormente, comenzando el milenio, la Corte Suprema hizo mención de la proporcionalidad como «criterio»y, a su vez, como «principio» general, pero sin asignarle un rol específico (véase, por ejemplo, Sentencia del 18 de febrero de 2000).

En esa misma década, la Casación civil sigue haciendo mención de la proporcionalidad como «criterio» sin un rol específico, por ejemplo, para referirse al margen de proporcionalidad entre las obligaciones de las partes (Sentencia del 19 de diciembre de 2005). Una referencia más concreta al rol específico de la proporcionalidad se observa en el año 2007, allí se hizo referencia a la proporcionalidad como criterio o postulado de «razonabilidad» con carácter o función excepcional, «conforme al cual corresponde al juez escrutar y sopesar

1 Sobre el principio de proporcionalidad, véase las siguientes sentencias de la Corte Constitucional: Acción de Tutela instaurada por $X$ con respecto al derecho a la educación y a la proporcionalidad de actos administrativos, Demanda de inconstitucionalidad contra el artículo 40, literal b, de la ley 48 de 1993; Acción de tutela instaurada por Juan de Jesús Jiménez contra FEBOR entidad cooperativa COOP-FEBOR; Demanda de inconstitucionalidad contra los artículos 14, 18 y 19 de la ley 344 de 1996, «Por la cual se dictan normas tendientes a la racionalización del gasto público, se conceden unas facultades y se expiden otras disposiciones»; Demanda de inconstitucionalidad contra el artículo 178 del decreto 1344 de 1970, tal y como fue modificado por el artículo $1^{\circ}$ del decreto 1809 de 1990; Demanda de inconstitucionalidad contra el artículo 97 de la ley 599 de 2000, «(p)or la cual se expide el Código Penal»; Demanda de inconstitucionalidad contra el artículo 41 de la ley 633 de 2000; Acción de tutela instaurada por Natalia Palacios Rojas y otros contra Colciencias e Icetex; Demanda de inconstitucionalidad contra el artículo 44 de la ley 782 de 2002, «Por medio de la cual se prorroga la vigencia de la ley 418 de 1997, prorrogada y modificada por la ley 548 de 1999 y se modifican algunas disposiciones»; Demanda de inconstitucionalidad contra los artículos 32 (parcial), 36 (parcial), 38, 39, 40 (parcial), 43, 44, 45, 46, 47, 48, y 49 de la ley 1333 de 2009, «Por la cual se establece el procedimiento sancionatorio ambiental y se dictan otras disposiciones». Sobre el alcance del principio de proporcionalidad como herramienta hermenéutica, véase las sentencias de los siguientes casos: Acción de Tutela instaurada por $\mathrm{X}$ con respecto al derecho a la educación y a la proporcionalidad de actos administrativos; Demanda de inconstitucionalidad contra el artículo 178 del decreto 1344 de 1970, tal y como fue modificado por el artículo 1ㅇ del decreto 1809 de 1990; Demanda de inconstitucionalidad contra los artículos 139 (parcial), 321 (parcial) y 324 (parcial) del decreto 2700 de 1991, "Por el cual se expiden las normas de procedimiento penal»; Demanda de inconstitucionalidad contra el artículo 228 de la ley 599 de 2000, «por la cual se expide el Código Penal».

NOTAS SOBRE

ALGUNOS

PRINCIPIOS

GENERALES

DEL DERECHO:

UNA REFLEXIÓN

A PARTIR DE

PRINCIPIOS

GENERALES Y

SU INFLUENCIA

EN LAS

OBLIGACIONES EN

LA EXPERIENCIA

JURÍDICA

COLOMBIANA

NOTES ABOUT

SOME GENERAL

PRINCIPLES OF

LAW: A VIEW OF

SOME GENERAL

PRINCIPLES AND

THEIR INFLUENCE

ON THE LAW OF

OBLIGATIONS

IN COLOMBIAN

LEGAL

EXPERIENCE 
los intereses en conflicto o tensión» (Sentencia del 29 de junio de 2007, consideración 4.6).

El principio de proporcionalidad cumple hoy en día una función indispensable para garantizar el postulado constitucionalista de los límites del poder público, esto es, que los jueces deberían emplear el procedimiento interpretativo del principio de proporcionalidad para garantizar a los ciudadanos el máximo goce de sus derechos fundamentales y evitar su arbitraria vulneración (Carbonell, 2007, p. 340). Como se sabe, este principio no es exclusivo del derecho penal o del constitucional, e influye en otras áreas del derecho — como en el derecho privado-, aunque con restricciones que, sin embargo, no excluyen su aplicación. Esta función de «razonabilidad» que se asigna ha sido reiterada en decisiones recientes, pero sin desarrollo y sin una línea jurisprudencial clara, apenas como mero criterio de razonabilidad o racionalidad, pero sin un desarrollo de sus funciones o de su alcance específico (véase Sentencia del 20 de agosto de 2014; Sentencia del 18 de enero de 2016).

\section{CONCLUSIONES}

No se conoce perfectamente un arte si no se conocen sus principios - como afirma Baldo degli Ubaldi en su Comentaria in digestum vetus: etiam quia non perfectae novit artem quia non movit principia artis $(1,1$, 1) - Los principios generales, bien sea encontrados o formulados de acuerdo con una u otra perspectiva, con una u otra orientación, están en la base del sistema jurídico como parte fundante, potissima, que explica y orienta lo que sigue, como un sello característico de un sistema en devenir histórico moldeado por y para los hombres (hominum causa), mejorado cotidianamente por obra de los juristas. Se trata de un sistema en desarrollo, cuyos momentos de fijación a lo largo del tiempo marcan el paso de una época y, sobre la base de lo anterior, impulsan el siguiente paso hacia nuevos momentos de fijación, de estabilización del derecho mediante la armonización jurídica. Esto es posible con el vehículo de los principios, guiado por los juristas.

Sin embargo, esta argumentación supone problemas que no es posible afrontar aquí. Lo cierto es que los principios se obtienen de la experiencia jurídica, del derecho, que es también una manifestación cultural de la humanidad, y los principios una formulación general del mismo derecho (Digesto 50, 17, 1 (Paulo)). Identificar y contribuir en la sistematización de principios es tarea fundamental del jurista, de la jurisprudencia, pero esa que Bartolo llamó «civilis sapientia», solo comparable con la metafísica y la teología. 
Es importante saber cuál es la función de las regulae o maximae, pero todavía más importante es el método lógico y la técnica de la ciencia del derecho -iurisprudentia - (Alpa, 1993, pp. 57ss.; véase Metzger, 2009, pp. 14ss.) al aplicar tales reglas o máximas, o bien, tales principios. Por su parte, la moderna teoría del derecho no nos dice cuáles son los principios jurídicos incorporados en cada ordenamiento. Esto solo puede decirlo la dogmática jurídica relacionada con el ordenamiento indagado, aunque muchos principios encuentran obviamente su expresión en las leyes. Tampoco nos dice cuáles deben ser esos principios, esto es la tarea de una filosofía de la justicia dice Ferrajoli (2007, pp. 33ss.). Ferrajoli señala la importancia de una teoría garantista del derecho que ofrezca la llave de lectura de las antinomias y de las lagunas presentes en el derecho vigente respecto de su modelo constitucional, una teoría tal permitiría redefinir la esfera pública de las garantías de los derechos fundamentales diseñadas por tal modelo y repensar las características tradicionales puramente estatal-legalistas tanto del positivismo jurídico como del constitucionalismo y de la democracia; y esto para adecuarlas a los nuevos lugares extra y supra estatales, así como los nuevos poderes y las nuevas asimetrías con sus respectivos remedios y garantías.

Pero, en realidad, es la tarea del jurista; una de sus funciones como sacerdote del ars iuris. La identificación, sistematización, contenido, alcance de los principios del derechode obligaciones cumplirían la función orientadora del proceso de armonización del derecho en Latinoamérica, tal y como lo ha demostrado el Grupo para la Armonización del Derecho en América Latina (GADAL), bajo la guía de prestigiosos juristas de los distintos países del continente. Pero ya antes la tarea se ha cumplido en parte en relación con las obligaciones de contrato, me refiero a la importante labor de otro grupo de prestigiosos juristas que han elaborado unos Principios latinoamericanos de Derecho de los Contratos (PLDC). En particular, sobre los PLDC, el trabajo realizado por destacados profesores del continente ha sido arduo y ha dado frutos. No se trata de crear una interacción con otros procesos de armonización contractual, sino más bien proponer innovaciones dentro del contexto de los aportes de los ordenamientos latinoamericanos, con novedades en materia de formación del contrato, incumplimiento y remedios. De igual modo, este esfuerzo es de la mayor importancia en aras de perfeccionar la legislación y contribuir con un derecho de contratos adaptado a las necesidades de nuestros países (véase Pizarro, 2017). Ese proceso es el reflejo de las distintas influencias que ha recibido la cultura jurídica del continente y cualquier tendencia hacia nacionalismos o preferencias en la orientación debe ser rechazada (véase Schmidt, 2017; también con énfasis en la idea de tener en cuenta la realidad social de los países latinoamericanos y no simplemente copiar modelos europeos, esto como exigencia fundamental para el buen resultado de una legislación).

NOTAS SOBRE

ALGUNOS

PRINCIPIOS

GENERALES

DEL DERECHO:

UNA REFLEXIÓN

A PARTIR DE

PRINCIPIOS

GENERALES Y

SU INFLUENCIA

EN LAS

OBLIGACIONESEN

LA EXPERIENCIA

JURÍDICA

COLOMBIANA

NOTES ABOUT

SOME GENERAL

PRINCIPLES OF

LAW: A VIEW OF

SOME GENERAL

PRINCIPLES AND

THEIR INFLUENCE

ON THE LAW OF

OBLIGATIONS

IN COLOMBIAN

LEGAL

EXPERIENCE 
Los principios no se expresan en forma de meras proposiciones normativas sin otra calificación más, sino que tienen propiedades lógicas específicas de argumentos normativos. Han de esclarecerse las propiedades lógicas de principios en sentido de razones para las ponderaciones o, designadas de otra forma, de argumentos normativos. Ellas demuestran en su estructura y formas de validez particularidades que pueden ser caracterizadas con el concepto de un deber ideal (Sieckmann, 2006, p. 15; véase Metzger, 2009, pp. 14ss.).

Con los principios, hablamos de un deber ideal que va más allá de lo mandado definitivamente, de lo realizable en los hechos: libertad, autonomía privada como ejercicio de esa libertad; reconocimiento de la dignidad del ser humano en las relaciones jurídicas obligatorias, por lo mismo de su igualdad; tratamiento equitativo y más productor de igualdad en tales relaciones; solidaridad entre seres humanos que participan de esas relaciones; comportamiento de buena fe, pundonoroso, probo, honesto en todos los ámbitos y en el ejercicio de aquella libertad y de aquella autonomía, ejercicio digno de derechos, proporcionado, en igualdad de condiciones, con equidad en el trato, y solidaridad entre personas. Hay pues una pretensión de obligatoriedad en los principios, pero, al mismo tiempo, hay una no exigencia de un cumplimiento estricto. Esto a pesar de que los principios son factor de progreso social. Entonces, se acude a un modelo procedimental para establecer el deber ideal por medio de la idea de optimización. Esto supone un mandato de reconocimiento de una norma, un mandato de ponderación y un mandato de optimización (Sieckmann, 2006, pp. 23ss.). El mandato de reconocimiento de una norma exige de los juzgadores aceptar una norma como válida. Los mandatos de ponderación son reglas procesales que exigen la ponderación de normas colisionantes (acerca de la estructura de las colisiones y de la ponderación entre principios véase, entre otros, Sieckmann, 2006, pp. 161ss.; también Carbonell, 2007; Beade \& Clérico, 2011; Bernal Pulido, 2005, 2009; Metzger, 2009, pp. 14ss.). Los mandatos de optimización ordenan que algo sea cumplido en la medida más grande posible, en lo relativo a las posibilidades reales y jurídicas. Estos expresan el contenido normativo definitivo de los principios (Sieckmann, 2006, pp. 23-24). Esta es una de las argumentaciones en la teoría general que tiene buen recibo en la práctica y goza de prestigio en la doctrina. No obstante, la perspectiva que me parece más adecuada para la armonización del derecho en Latinoamérica es aquella que parte de la idea de principio como parte fuerte, fundante, que estructura y explica lo que sigue. Así, pues, se trata de una perspectiva que se encuentra en la búsqueda, mediante una perspectiva diacrónica, de los principios generales del sistema de derecho romano y sus recientes desarrollos.

Conviene siempre recordar que la ciencia jurídica debe ser, como decía Savigny, «orgánicamente progresiva», atenta siempre al «lazo 
vivo» entre el presente y el pasado. Por lo que la tarea fundamental del jurista moderno debe consistir en la «penetración intelectual, adaptación y rejuvenecimiento de la materia jurídica tal y como nos ha sido transmitida» ya que no hay «existencia humana completamente separada e independiente [...] cada época crea su propio mundo jurídico, no para sí misma y arbitrariamente sino en una unión indisoluble con la totalidad del pasado» (Zimmermann, 2010, p. 33).

Frente a los desafíos que vienen, no solo en el área del derecho contractual, sino también respecto del llamado bioderecho, debemos cuestionarnos sobre la autenticidad de las instituciones y sobre la madurez o adultez del derecho y de los juristas en Latinoamérica. Y la respuesta ya se ha comenzado a dar, como se dijo. En parte a estos desafíos ya ha dado respuesta la doctrina del continente con la redacción de los Principios latinoamericanos de Derecho de los Contratos (PLDC), y con los trabajos del GADAL sobre un Código Marco de Obligaciones para América Latina. Nos corresponde auscultarnos y revisar los hechos para una mayor inserción en el concierto universal. «Con todo, [como enseñaba Fernando Hinestrosa] en materia jurídica, donde confluyen afectos, pasiones, hábitos, creencias, intereses, técnicas, más que la creatividad, es necesario procurar una respuesta cabal al sentir nacional, a las aspiraciones colectivas, dentro de un sentido de justicia y de dignidad de la persona humana, una exigencia universal» (Hinestrosa, 1997, p. 15).

REFERENCIAS

Alpa, G. (1993). I principi generali. Milán: Giuffrè.

Autores varios (2012). Informe Colombia. En C. Pizarro (coord.), El derecho de los contratos en Latinoamérica: bases para unos principios de derecho de los contratos (pp. 207-295). Bogotá: Universidad Externado de Colombia.

Beade, G. \& Clérico, L. (eds.) (2011). Desafios de la ponderación. Bogotá: Universidad Externado de Colombia.

Becker, M. (2003). Der unfaire Vertrag. Tubinga: Mohr.

Benítez Caorsi, J. (2013). Solidaridad contractual: noción posmoderna del contrato. Madrid: Reus.

Berlin, I. (1993). Cuatro ensayos sobre la libertad. Madrid: Alianza Editorial.

Bernal Pulido, C. (2005). El derecho de los derechos. Bogotá: Universidad Externado de Colombia.

Bernal Pulido, C. (2009). El neoconstitucionalismo y la normatividad en el derecho. Bogotá: Universidad Externado de Colombia.

NOTAS SOBRE

ALGUNOS

PRINCIPIOS

GENERALES

DEL DERECHO:

UNA REFLEXIÓN

A PARTIR DE

PRINCIPIOS

GENERALES Y

SU INFLUENCIA

EN LAS

OBLIGACIONES EN

LA EXPERIENCIA

JURÍDICA

COLOMBIANA

NOTES ABOUT

SOME GENERAL

PRINCIPLES OF

LAW: A VIEW OF

SOME GENERAL

PRINCIPLES AND

THEIR INFLUENCE

ON THE LAW OF

OBLIGATIONS

IN COLOMBIAN

LEGAL

EXPERIENCE 
Bernal Pulido, C. (2014). Elprincipio de proporcionalidady los derechos fundamentales: El principio de proporcionalidad como criterio para determinar el contenido de los derechos fundamentales vinculante para el Legislador (4ta. ed.). Bogotá: Universidad Externado de Colombia.

Betti, E. (2015). La estructura de la obligación romana y el problema de su génesis (J.F. Chamie, trad.). Bogotá: Universidad Externado de Colombia.

Bianca, C.M. (2000). Diritto civile III: Il contratto. Milán: Giuffrè.

Cartwright, J. (2018). Proyectos de armonización: ¿lecciones de la experiencia europea? Latin American Legal Studies, 2, 1-24.

Carbonell, M. (coord.) (2007). El principio de proporcionalidad en el Estado constitucional. Bogotá: Universidad Externado de Colombia.

Carvajal Sánchez, B. (2012). La dignidad de la persona humana antes de la Constitución de 1991: pequeña historia de un gran principio. En F.R. Barbosa Delgado (ed.), Historia del derecho público en Colombia I (pp. 29-52). Bogotá: Universidad Externado de Colombia.

Carvajal Sánchez, B. (2013). Potestad reglamentaria. Control y bloque de legalidad lato sensu. Libertad de profesión u oficio. Principio de dignidad humana. Consejo de Estado, Sala de lo Contenciosos Administrativo, Sección Primera, sentencia del 14 de enero de 1976, Anales, t. xc, pp. 234-241. En A.F. Ospina Garzón (ed.), Los grandes fallos de la jurisprudencia administrativa colombiana (pp. 73-86). Bogotá: Universidad Externado de Colombia.

Castronovo, C. \& Mazzamuto, S. (2007). Manuale di diritto privato europeo (vol. 2). Milán: Giuffrè.

Correa Henao, M. (2009). Libertad de empresa en el Estado social de Derecho. Bogotá: Universidad Externado de Colombia.

Cortés, E. (2006). Fluidez y certeza del derecho: ihacia un sistema abierto de fuentes?. En J. Adame Goddard (coord.), Derecho civil y romano: Culturas y sistemas jurídicos comparados (pp. 553-580). Ciudad de México: UNAM.

Cortés, E. (2009a). La culpa contractual en el sistema jurídico latinoamericano (2da. ed.). Bogotá: Universidad Externado de Colombia.

Cortés, E. (2009b). Responsabilidad civil y daños a la persona. Bogotá: Universidad Externado de Colombia.

Cortés, E. (2011). Los deberes del acreedor. En Grupo para la Armonización del Derecho Privado Latinoamericano (GADAL), Obligaciones, contratos, responsabilidad (pp. 202-212). Bogotá: Universidad Externado de Colombia.

Chamie, J.F. (2012). El principio general de reductio ad aequitatem por desequilibrio contractual. Revista de Derecho Privado, 22, 219-275.

Chamie, J.F. (2013). La adaptación del contrato por eventos sobrevenidos. Bogotá: Universidad Externado de Colombia.

Chamie, J.F. (s.f.). La corrección del contrato (manuscrito inédito). 
Chevallier, J. (2011). El estado posmoderno (O. Pérez, trad.). Bogotá: Universidad Externado de Colombia.

Cuffaro, V. (ed.) (2008). Codice del consumo e norme collegate. Milán: Giuffrè.

D’Amico, G. (1993). Libertà di scelta del tipo contrattuale e frode alla legge. Milán: Giuffrè.

Fabre-Magnan, M. (2004). Les obligations. París: PUF.

Facco, J. (2017). Vicisitudes de la buena fe negocial: reflexiones histórico-comparativas. Bogotá: Universidad Externado de Colombia.

Falco, G. (2010). La buona fede e l'abuso del diritto: principi, fattispecie e casistica. Milán: Giuffrè.

Ferrajoli, L. (2007). Principia iuris: Teoria del diritto e della democrazia 1. Teoria del diritto. Roma-Bari: Laterza.

Ferrante, A. (2016). ¿Quimera o Fénix? El recorrido europeo y latinoamericano hacia un derecho común de contratos. Revista de Derecho Privado, 30, 107-127. doi: 10.18601/01234366.n30.05

Flórez, J.F. (2015). La libertad como único fundamento de la libertad. Serie de Documentos de Trabajo, 71 (Departamento de derecho constitucional Universidad Externado de Colombia, Bogotá).

Franco Victoria, D. (2011). Obligaciones civiles y fuente constitucional. En Grupo para la Armonización del Derecho Privado Latinoamericano (GADAL), Obligaciones, contratos, responsabilidad (pp. 213-250). Bogotá: Universidad Externado de Colombia.

Gamboa Morales, E. (2003). El arbitraje en equidad. Bogotá: Academia.

Giraldo Bustamante, C. (2014). El contrato y la justicia: una relación permanente y compleja. Bogotá: Universidad Externado de Colombia.

Gramunt, M. \& Florensa, C. (dirs.) (2017). Codificación y reequilibrio de la asimetría negocial. Madrid: Dykinson.

Grosso, G. (1976). Tradizione e misura umana del diritto. Milán: Edizioni di Comunità.

Grosso, G. (2011). Las obligaciones: contenido y requisitos de la prestación (F. Hinestrosa, trad.). Bogotá: Universidad Externado de Colombia.

Henao, J.C. (1998). El daño. Bogotá: Universidad Externado de Colombia.

Hinestrosa, F. (1983). La responsabilidad civil. En Escritos varios (pp. 673-712). Bogotá: Universidad Externado de Colombia.

Hinestrosa, F. (1997). Los principios generales del derecho: aplicación y perspectivas. Revista de Derecho Privado, 1, 3-16.

Hinestrosa, F. (2014). Codificación, descodificación y recodificación. Revista de Derecho Privado, 27, 3-13.

NOTAS SOBRE

ALGUNOS

PRINCIPIOS

GENERALES

DEL DERECHO:

UNA REFLEXIÓN

A PARTIR DE

PRINCIPIOS

GENERALES Y

SU INFLUENCIA

EN LAS

OBLIGACIONESEN

LA EXPERIENCIA

JURÍDICA

COLOMBIANA

NOTES ABOUT

SOME GENERAL

PRINCIPLES OF

LAW: A VIEW OF

SOME GENERAL

PRINCIPLES AND

THEIR INFLUENCE

ON THE LAW OF

OBLIGATIONS

IN COLOMBIAN

LEGAL

EXPERIENCE 
Hinestrosa, F. (2015). Tratado de las obligaciones I. Bogotá: Universidad Externado de Colombia.

Insignares-Cera, S. \& Molinares-Hassan, V. (2012). Juicio integrado de constitucionalidad: análisis de la metodología utilizada por la corte constitucional colombiana. Universitas, 61 (124), 91-118.

Kaufmann, A. (1999). Filosofía del derecho (L. Villar Borda, trad.). Bogotá: Universidad Externado de Colombia.

Koteich Katib, M. (2012). La reparación del daño como mecanismo de tutela de la persona. Bogotá: Universidad Externado de Colombia.

Kötz, H. \& Flessner, A. (1997). European Contract Law (T. Weir, trad.). Oxford: Oxford University Press.

López Roca, L.F. (2012). El principio de igualdad en la actividad financiera. Bogotá: Universidad Externado de Colombia.

Mantello, M. (2007). Autonomia dei privati e problemi giuridici della solidarietà. Milán: Giuffrè.

Metzger, A. (2009). Extra legem, intra ius: allgemeine Rechtsgrundsätze im europäischen Privatrecht. Tubinga: Mohr Siebeck.

Momberg, R. (2018). Los principios latinoamericanos de derecho de los contratos: naturaleza, fines y proyecciones. Latin American Legal Studies, 2, 51-66.

Momberg, R. \& Vogenauer, S. (eds.) (2017). The Future of Contract Law in Latin America: The Principles of Latin American Contract Law. Oxford: Hart Publishing.

Montesquieu (1869). De l'esprit des lois. París: Garnier Frères.

Morales Hervias, R. (2010). Las patologías y los remedios del contrato. Tesis inédita para obtener el grado de Doctor en Derecho por la Pontificia Universidad Católica del Perú. Recuperado de http://tesis.pucp.edu.pe/repositorio// handle/123456789/4682

Morales Hervias, R. (2013). Los contratos con deberes de protección: a propósito de la vinculación entre el derecho constitucional y el derecho civil. Derecho PUCP, 71, 53-75.

Morales Hervias, R. (2016). Los abusos contractuales y sus remedios: desde el derecho romano hasta la codificación civil y proyectos de armonización. En J. Adame y H. Heredia (eds.), Estudios latinoamericanos de derecho romano (pp. 353-377). Ciudad de México: UNAM.

Morales Moreno, A. (2014). Los Principios latinoamericanos de Derecho de los Contratos: un debate abierto sobre las grandes cuestiones jurídicas de la contratación. Anuario de Derecho Civil, 67(1), 227-254.

Neme Villarreal, M. (2006). El principio de buena fe en materia contractual en el sistema jurídico colombiano. Revista de Derecho Privado, 11, 79-125. 
Neme Villarreal, M. (2010). La buena fe en el derecho romano: la extensión del deber de actuar conforme a buena fe en materia contractual. Bogotá: Universidad Externado de Colombia.

Ordoqui, G. (2012). La buena fe contractual. Bogotá: Ibáñez.

Pizarro, C. (2017). The Principles of Latin American Contract Law: A General Introduction. En R. Momberg y S. Vogenauer (eds.), The Future of Contract Law in Latin America: The Principles of Latin American Contract Law (pp. 23-28). Oxford: Hart Publishing.

Pothier, R. (1761). Traité des obligations. París: Chez Debure.

Santaella, H. (2010). El régimen constitucional de la propiedad privada y su garantía en Colombia: Análisis fundamentado en el estudio de la garantía de la propiedad privada en los ordenamientos constitucionales alemán y español. Tesis inédita para obtener el grado de Doctor en Derecho por la Universidad Autónoma de Madrid, Facultad de Derecho. Recuperado de http:/hdl.handle.net/10486/5246

Santamaria, F. (2012). Autonomia privata e statuto del contribuente. Milán: Giuffrè.

Schipani, S. (2010). La codificación del derecho romano común (J.F. Chamie, trad.). Bogotá: Universidad Externado de Colombia.

Schmidt, J.P. (2017). The «Principles of Latin American Contract Law» Against the Background of Latin American Legal Culture: A European Perspective. En R. Momberg y S.Vogenauer (eds.), The Future of Contract Law in Latin America: The Principles of Latin American Contract Law (pp. 57-95). Oxford: Hart Publishing.

Scognamiglio, R. (1971). Contratti in generale (3ra. ed.). Milán: Vallardi.

Sieckmann, J.R. (2006). El modelo de los principios del derecho (C. Calderón, trad.). Bogotá: Universidad Externado de Colombia.

Tamayo Jaramillo, J. (2007). Tratado de responsabilidad civil II. Bogotá: LEGIS.

Thomasius, C. (1706). Dissertationum academicarum (vol. 4). Halle.

NOTAS SOBRE

ALGUNOS

PRINCIPIOS

GENERALES

DEL DERECHO:

UNA REFLEXIÓN

A PARTIR DE

PRINCIPIOS

GENERALES Y

SU INFLUENCIA

EN LAS

OBLIGACIONES EN

LA EXPERIENCIA

JURÍDICA

COLOMBIANA

NOTES ABOUT

SOME GENERAL

PRINCIPLES OF

LAW: A VIEW OF

SOME GENERAL

PRINCIPLES AND

THEIR INFLUENCE

ON THE LAW OF

OBLIGATIONS

IN COLOMBIAN

LEGAL

EXPERIENCE

Tisseyre, S. (2012). Le rôle de la bonne foi en droit des contrats. Aix-En-Provence: Puam.

Trimarchi, P. (2011). Istituzioni di diritto privato (19na. ed.). Milán: Giuffrè.

Upegui Mejía, J.C. (2009). Doce tesis en torno al concepto de Estado social de Derecho. Discurso jurisprudencial: elementos, usos. Bogotá: Universidad Externado de Colombia.

Webber, G. (2010). Proportionality, Balancing, and the Cult of Constitutional Rights Scholarship. Canadian Journal of Law EJ Jurisprudence, 23(1), 179-202. doi: $10.1017 / S 0841820900004860$

Zimmermann, R. (2010). Derecho romano, derecho contemporáneo, derecho europeo (J. Rodríguez Olmos, trad.). Bogotá: Universidad Externado de Colombia. 


\section{Jurisprudencia, normativa y otros documentos legales}

Acción de tutela instaurada por Ana Rosa Serna con respecto a la responsabilidad constitucional de las autoridades municipales por los riegos a la vida y a la integridad personal que causan con ocasión de la realización de obras públicas y a la equidad en la aplicación concreta del derecho, T-518/98 (Corte Constitucional [Colombia], 22 de setiembre de 1998).

Acción de tutela instaurada por Angie Daniela Salazar Zapata en contra de Coomeva EPS, T-381/14 (Corte Constitucional [Colombia], 13 de junio de 2014).

Acción de tutela instaurada por Danilo Molina con respecto al derecho a la salud, a la libertad de locomoción y a la libertad de residencia, T-487/92 (Corte Constitucional [Colombia], 11 de agosto de 1992).

Acción de tutela instaurada por Jaime Alberto Cantor, Carlos Sánchez y Lino Alonso con respecto al derecho al ambiente sano, a la calidad de vida y al derecho de petición, T-125/95 (Corte Constitucional [Colombia], 22 de marzo de 1995).

Acción de tutela instaurada por Jorge Isaac Escobar en contra de la cooperativa Coopserp, T-222/04 (Corte Constitucional [Colombia], 08 de marzo de 2004).

Acción de tutela instaurada por Juan de Jesús Jiménez contra FEBOR entidad cooperativa COOP-FEBOR, T-230/94 (Corte Constitucional [Colombia], 13 de mayo de 1994).

Acción de tutela instaurada por Juan Gustavo Rua Cardona con respecto al derecho al trabajo, T-640/99 (Corte Constitucional [Colombia], 31 de agosto de 1999).

Acción de tutela instaurada por Marcelino Rodríguez Rojas con respecto a la eficacia directa de los derechos fundamentales frente a particulares, el concepto de posición dominante, la función social de la empresa y la destrucción de oportunidades laborales como acto ilegítimo de retaliación empresarial, T-375/97 (Corte Constitucional [Colombia], 14 de agosto de 1997).

Acción de tutela instaurada por Natalia Palacios Rojas y otros contra Colciencias e Icetex, T-677/04 (Corte Constitucional [Colombia], 15 de julio de 2004).

Acción de tutela instaurada por Neyla del Carmen Navas Contreras en representación de su hermano Juan Manuel Contreras contra el Instituto de Seguro Social, T-075/02 (Corte Constitucional [Colombia], 07 de febrero de 2002).

Acción de Tutela instaurada por Shirley Mireya Ospitia Hernández contra La Empresa METROAGUA S.A. E.S.P., T-552/11 (Corte Constitucional [Colombia], 07 de julio de 2011).

Acción de Tutela instaurada por X con respecto al derecho a la educación y a la proporcionalidad de actos administrativos, T-015/94 (Corte Constitucional [Colombia], 25 de enero de 1994). 
Acciones de tutela instauradas por Austreberto de Ávila Ríos y otros, y Edwin Campo Vega (personero de El Arenal (Bolívar)) contra Electrocosta S.A. E.S.P., T-881/02 (Corte Constitucional [Colombia], 17 de octubre de 2002).

Acciones de tutela instauradas por Gilberto Gaviria Posada y Luis Enrique Villalobos Castaño contra entidades bancarias particulares, SU-157/99 (Corte Constitucional [Colombia], 10 de marzo de 1999).

Acciones de tutela instauradas por Nelcy Johana Marín Sanabria e Ingrid Jhoana Chávez Coronado contra la Sexta Brigada Distrito Militar de Reclutamiento Ibagué y el Comandante del Batallón Jaime Rooke, T-342/09 (Corte Constitucional [Colombia], 18 de mayo de 2009).

Amparo de Jesús Ramírez Suárez c. Hospital San Vicente de Paul de Lorica y otro, Apelación Sentencia - Acción de Reparación Directa, Radicación 23001-23-31000-2001-00278-01(28804) (Consejo de Estado [CE] [Colombia], Sala de lo Contencioso Administrativo, Sección Tercera, 28 de agosto de 2014).

Ana Rita Alarcón vda. de Gutiérrez y otros c. Municipio de Pereira, Acción de Reparación Directa (Apelación Sentencia - Sentencia de Unificación), Radicación 66001-23-31-000-2001-00731-01(26251) (Consejo de Estado [CE] [Colombia], Sala de lo Contencioso Administrativo, Sección Tercera, 28 de agosto de 2014).

Codice civile [Código Civil] (Italia).

Código Marco de Obligaciones para América Latina, elaborado por el Grupo para la Armonización del Derecho en América Latina (GADAL). Recuperado de https:/gadal.uexternado.edu.co/codigo-marco/version-castellana/

Constitución Política de Colombia (1991).

Cooperativa Multiactiva de Empleados de Distribuidoras de Drogas (Copservir Ltda) c. Banco de Bogotá, Bancolombia, Interbanco, Banco de Occidente, Bancafé, Granahorrar y Banco Agrario de Colombia, T-468/03 (Corte Constitucional [Colombia], 05 de junio de 2003).

Demanda de inconstitucionalidad contra el artículo 19 de la Ley 256 de 1996 «por la cual se dictan normas sobre competencia desleal», C-535/97 (Corte Constitucional [Colombia], 23 de octubre de 1997).

Demanda de inconstitucionalidad contra el artículo 38 numeral 1 del Código de Procedimiento Civil, C-1547/00 (Corte Constitucional [Colombia], 21 de noviembre de 2000).

Demanda de inconstitucionalidad contra el artículo 40, literal b, de la Ley 48 de 1993, C-022/96 (Corte Constitucional [Colombia], 23 de enero de 1996).

Demanda de inconstitucionalidad contra el artículo 41 de la Ley 633 de 2000, C-616/02 (Corte Constitucional [Colombia], 06 de agosto de 2002).

Demanda de inconstitucionalidad contra el artículo 44 de la Ley 782 de 2002, «Por medio de la cual se prorroga la vigencia de la Ley 418 de 1997, prorrogada 
y modificada por la Ley 548 de 1999 y se modifican algunas disposiciones», C-923/2005 (Corte Constitucional [Colombia], 06 de setiembre de 2005).

Demanda de inconstitucionalidad contra el artículo 97 de la Ley 599 de 2000, «(p)or la cual se expide el Código Penal», C-916/02 (Corte Constitucional [Colombia], 29 de octubre de 2002).

Demanda de inconstitucionalidad contra el artículo 178 del decreto 1344 de 1970, tal y como fue modificado por el artículo 1o del decreto 1809 de 1990, C-309/97 (Corte Constitucional [Colombia], 25 de junio de 1997).

Demanda de inconstitucionalidad contra el artículo 205 del decreto 1355 de 1970 «Por el cual se dictan normas sobre policía», C-087/00 (Corte Constitucional [Colombia], 02 de febrero de 2000).

Demanda de inconstitucionalidad contra el artículo 228 de la Ley 599 de 2000, «por la cual se expide el Código Penal», C-392/02 (Corte Constitucional [Colombia], 22 de mayo de 2002).

Demanda de inconstitucionalidad contra el parágrafo del artículo 164 del decreto ley 1344 de 1970, Código Nacional de Tránsito Terrestre, C-521/98 (Corte Constitucional [Colombia], 23 de setiembre de 1998).

Demanda de inconstitucionalidad contra los artículos 14, 18 y 19 de la Ley 344 de 1996, «Por la cual se dictan normas tendientes a la racionalización del gasto público, se conceden unas facultades y se expiden otras disposiciones», C-584/1997 (Corte Constitucional [Colombia], 13 de noviembre de 1997).

Demanda de inconstitucionalidad contra los artículos 139 (parcial), 321 (parcial) y 324 (parcial) del Decreto 2700 de 1991, «Por el cual se expiden las normas de procedimiento penal», C-475/1997 (Corte Constitucional [Colombia], 25 de setiembre de 1997).

Demanda de inconstitucionalidad contra los artículos 252 (total) y 373 (parcial) del Código de Comercio, C-865/04 (Corte Constitucional [Colombia], 07 de setiembre de 2004).

Demanda de inconstitucionalidad contra los artículos 3o. (parcial), 14; 16, 21, $22,23,24,29,30,33,36,37,44,45$ y 52 (parciales); 53 y 57; 60 y 64 (parciales); 65; 69 (parcial); 72, 73, 77, 79, y 84; 86 (parcial); 87, 89, 90, 91, 98, 99, 101 y 109; 111 y 112 (parciales); 113, 114, 115, 116, 117, y 119; 121, 123, 125, 139, 147, 150 y 153 (parciales) y el artículo 168 de la Ley 65 de 1993, «por la cual se expide el Código Penitenciario y Carcelario», C-394/95 (Corte Constitucional [Colombia], 07 de setiembre de 1995).

Demanda de inconstitucionalidad contra los artículos 32 (parcial), 36 (parcial), 38, 39, 40 (parcial), 43, 44, 45, 46, 47, 48, y 49 de la Ley 1333 de 2009, «Por la cual se establece el procedimiento sancionatorio ambiental y se dictan otras disposiciones», C-703/2010 (Corte Constitucional [Colombia], 06 de setiembre de 2010).

Gonzalo Cuellar Penagos y otros c. Ministerio de Defensa - Ejército Nacional, Apelación Sentencia - Acción de Reparación Directa, Radicación 50001-23. 
15-000-1999-00326-01(31172) (Consejo de Estado [CE] [Colombia], Sala de lo Contencioso Administrativo, Sección Tercera, 28 de agosto de 2014).

Jurgen Huelsz, en nombre propio, y en representación de su hija, y de la Sociedad Madsen \& Huelsz Ltda. c. Juzgado 13 Civil de Circuito de Bogotá, Juzgado 31 Civil de Circuito de Bogotá, Superintendencia Bancaria, Fondo de Garantías de las Instituciones Financieras, Banco de Bogotá, Banco BBVA -Ganadero, T-520/03 (Corte Constitucional [Colombia], 26 de junio de 2003).

Leonardo David Mizzar Vargas c. Policía Metropolitana de Barranquilla, T-673/13 (Corte Constitucional [Colombia], 24 de setiembre de 2013).

Ley 446 de 1998, Por la cual se adoptan como legislación permanente algunas normas del Decreto 2651 de 1991, se modifican algunas del Código de Procedimiento Civil, se derogan otras de la Ley 23 de 1991 y del Decreto 2279 de 1989, se modifican y expiden normas del Código Contencioso Administrativo y se dictan otras disposiciones sobre descongestión, eficiencia y acceso a la justicia, Diario Oficial, 43.335, 08 de julio de 1998.

Ley 497 de 1999, Por la cual se crean los jueces de paz y se reglamenta su organización y funcionamiento, Diario Oficial, 43.499, 11 de febrero de 1999.

Ley 1480 de 2011, Por medio de la cual se expide el Estatuto del Consumidor y se dictan otras disposiciones, Diario Oficial, 48.220, 12 de octubre de 2011.

Normativa Común de Compraventa Europea (CESL). Propuesta de Reglamento del Parlamento Europeo y del Consejo relativo a una normativa común de compraventa europea /* COM/2011/0635 final - 2011/0284 (COD) */. Recuperado de https://eur-lex.europa.eu/legal-content/ES/ALL/?uri=celex:52011PC0635

P7 TA(2014)0159 Normativa común de compraventa europea ***I Resolución legislativa del Parlamento Europeo, de 26 de febrero de 2014, sobre la propuesta de Reglamento del Parlamento Europeo y del Consejo relativo a una normativa común de compraventa europea (COM(2011)0635 - C7-0329/20112011/0284(COD)) P7 TC1-COD(2013)0013 Posición del Parlamento Europeo aprobada en primera lectura el 26 de febrero de 2014 con vistas a la adopción del Reglamento (UE) $n^{\circ}$.../2014 del Parlamento Europeo y del Consejo relativo a una normativa común de compraventa europea, Diario Oficial, C 285, 29 de agosto de 2017, 638-724. Recuperado de https://eur-lex. europa.eu/legal-content/ES/ALL/?uri=CELEX:52014AP0159

Principios latinoamericanos de Derecho de los Contratos (PLDC). Recuperado de http://pldc.uexternado.edu.co/el-proyecto-2/

Principles, Definitions and Model Rules of European Private Law: Draft Common Frame of Reference (DCFR), preparados por Study Group on a European Civil Code y Research Group on EC Private Law (Acquis Group), parcialmente sobre la base de una versión revisada de los Principles of European Contract Law (C. von Bar \& otros, eds.). Recuperado de https://www.law.kuleuven.be/personal/ mstorme/european-private-law_en.pdf

Sentencia del 01 de abril de 2003, Recurso de Casación, Expediente 6499 (Corte Suprema de Justicia [Colombia], Sala de Casación Civil).

NOTAS SOBRE

ALGUNOS

PRINCIPIOS

GENERALES

DEL DERECHO:

UNA REFLEXIÓN

A PARTIR DE

PRINCIPIOS

GENERALES Y

SU INFLUENCIA

EN LAS

OBLIGACIONES EN

LA EXPERIENCIA

JURÍDICA

COLOMBIANA

NOTES ABOUT SOME GENERAL PRINCIPLES OF

LAW: A VIEW OF

SOME GENERAL

PRINCIPLES AND

THEIR INFLUENCE

ON THE LAW OF

OBLIGATIONS

IN COLOMBIAN

LEGAL

EXPERIENCE 
Sentencia del 01 de agosto de 2014, Recurso de Casación, Radicación 11001-3110-013-2005-01034-01 [SC10223-2014] (Corte Suprema de Justicia [Colombia], Sala de Casación Civil).

Sentencia del 01 de diciembre de 2008, Recurso de Casación, Expediente 41298-3103-001-2002-00015-01 [SC-101-2008] (Corte Suprema de Justicia [Colombia], Sala de Casación Civil).

Sentencia del 05 de agosto de 2014, Radicación 11001-31-03-003-2003-0066001 [SC10297-2014] (Corte Suprema de Justicia [Colombia], Sala de Casación Civil).

Sentencia del 06 de julio de 2007, Recurso de Casación, Expediente 11001-3103-037-1998-00058-01 (Corte Suprema de Justicia [Colombia], Sala de Casación Civil).

Sentencia del 07 de mayo de 1968, Gaceta Judicial, 124(2297-2299), 106-125 (Corte Suprema de Justicia [Colombia], Sala de Casación Civil y Agraria).

Sentencia del 07 de octubre de 2009, Recurso de Casación, Expediente 05360 31-03-001-2003-00164-01 (Corte Suprema de Justicia [Colombia], Sala de Casación Civil).

Sentencia del 08 de setiembre de 2011, Recurso de Casación, 11001-3103-0262000-04366-01 (Corte Suprema de Justicia [Colombia], Sala de Casación Civil).

Sentencia del 09 de diciembre de 2011, Recurso de Casación, 25843-3184-0012005-00140-01 (Corte Suprema de Justicia [Colombia], Sala de Casación Civil).

Sentencia del 09 de setiembre de 2015, Recurso de Casación, Radicación 05001310301120060008501 [SC12018-2015] (Corte Suprema de Justicia [Colombia], Sala de Casación Civil).

Sentencia del 12 de setiembre de 2000, Recurso de Casación, 5397 (Corte Suprema de Justicia [Colombia], Sala de Casación Civil).

Sentencia del 15 de julio de 2004, Recurso de Casación, Expediente 7513 (Corte Suprema de Justicia [Colombia], Sala de Casación Civil).

Sentencia del 18 de enero de 2016, Recurso de Casación, Radicación 05001-3110-009-2008-00430-01 [AC080-2016] (Corte Suprema de Justicia [Colombia], Sala de Casación Civil).

Sentencia del 18 de febrero de 2000, Recurso de Casación, Expediente 5179 (Corte Suprema de Justicia [Colombia], Sala de Casación Civil).

Sentencia del 19 de diciembre de 2005, Recurso de Casación, Expediente 0800131030041996-10274-02 [SC-360-2005] (Corte Suprema de Justicia [Colombia], Sala de Casación Civil).

Sentencia del 20 de agosto de 2014, Recurso de Súplica, Radicación 11001-0203000-2013-00173-00 [ac 4773] (Corte Suprema de Justicia [Colombia], Sala de Casación Civil). 
Sentencia del 20 de mayo de 1936, Gaceta Judicial, 43(1904), 44-60 (Corte Suprema de Justicia [Colombia], Sala de Casación Civil y Agraria).

Sentencia del 23 de setiembre de 1993, Recurso de Casación, Expediente 3961 (Corte Suprema de Justicia [Colombia], Sala de Casación Civil).

NOTAS SOBRE

Sentencia del 24 de octubre de 1957, Gaceta Judicial, 86(2188-2189-2190), 472 479 (Corte Suprema de Justicia [Colombia], Sala de Casación Civil y Agraria).

Sentencia del 27 de julio de 2015, Recurso de Casación, Radicación 1100131030422009-00788-01 [SC9720-2015] (Corte Suprema de Justicia [Colombia], Sala de Casación Civil).

Sentencia del 28 de agosto de 2015, Recurso de Casación, Radicación 11001-3103-010-2007-00095-01 [SC11504-2015] (Corte Suprema de Justicia [Colombia], Sala de Casación Civil).

Sentencia del 29 de junio de 2007, Recurso de Casación, Expediente 05001-3110-006-2000-00751-01 [SC-076-2007] (Corte Suprema de Justicia [Colombia], Sala de Casación Civil).

UNIDROIT Principles of International Commercial Contracts (UNIDROIT, International Institute for the Unification of Private Law, 2016). Recuperado de https://www.unidroit.org/instruments/commercialcontracts/unidroit-principles-2016

ALGUNOS

PRINCIPIOS

GENERALES

DEL DERECHO: UNA REFLEXIÓN

A PARTIR DE

PRINCIPIOS

GENERALES Y

SU INFLUENCIA

EN LAS

OBLIGACIONES EN

LA EXPERIENCIA

JURÍDICA

COLOMBIANA

NOTES ABOUT

SOME GENERAL

PRINCIPLES OF

LAW: A VIEW OF

SOME GENERAL

PRINCIPLES AND

THEIR INFLUENCE

ON THE LAW OF

OBLIGATIONS

IN COLOMBIAN

LEGAL

EXPERIENCE 